\title{
"No sé qué tiene tu voz / cantando que el alma roba". Apostillas musicales a Los celos hacen estrellas
}

\author{
"I Do Not Know What It Is about Your \\ Singing Voice / that Robs the Soul". Musical \\ Annotations on Los celos hacen estrellas
}

El presente trabajo pretende actualizar y completar la información sobre las fuentes musicales conservadas de la zarzuela Los celos hacen estrellas de Juan Vélez de Guevara y Juan Hidalgo con vistas a una inminente nueva edición de dicha obra dramática. Además de atender a la literatura secundaria generada hasta la fecha, se presta especial atención al estudio de las composiciones actualmente conservadas, por una parte, en la Sección de Música de la Biblioteca Nacional de Madrid, y, por otra, a las fuentes "a lo humano" y "a lo divino" que atesora el archivo musical de la catedral de Valladolid, todo lo cual ha permitido corregir o matizar cuestiones de pertinencia o autoría de uno de los tonos asociados a dicha producción dramática, así como comprender de manera más ajustada aspectos relativos a la circulación, recepción y asimilación de la música teatral en el último tercio del siglo XVII.

Palabras clave: zarzuela, Juan Vélez de Guevara, Juan Hidalgo, tonos teatrales, villancico, contrafactum, Francisco Guerau, Miguel Gómez Camargo, circulación, recepción.

This article aims to update and complete information about the extant musical sources of the zarzuela Los celos hacen estrellas by Juan Vélez de Guevara and Juan Hidalgo with a view to an imminent new edition of this stage work. Apart from addressing the secondary literature that has been generated to date, special attention is paid to the study of the compositions presently preserved in the Sección de Música at the Biblioteca Nacional de Madrid on the one hand, and to the "a lo divino" (sacred) and "a lo humano" (secular) sources held at the music archive of Valladolid Cathedral on the other. This has permitted issues of pertinence and the authorship of one of the tonos (songs) associated with this work to be corrected and qualified, as well as details relating to the circulation, reception and assimilation of stage music during the last third of the 17th century to be more clearly understood.

Keywords: zarzuela, Juan Vélez de Guevara, Juan Hidalgo, theatrical tonos (songs), villancico, contrafactum, Francisco Guerau, Miguel Gómez Camargo, circulation, reception. 


\section{Introducción}

Los editores modernos de la zarzuela Los celos hacen estrellas fechan su estreno el 22 de diciembre de 1672, onomástica de la reina Mariana de Austria, y su repetición para el cumpleaños del rey, en noviembre del siguiente año ${ }^{1}$. La copia manuscrita conservada en Viena ${ }^{2}$ de la fiesta teatral, con las acuarelas de Herrera el Mozo, debió llevarse a cabo en Madrid en los primeros meses de 1673, tras lo cual se envió a la corte austriaca de los Habsburgo, hecho éste que está documentado ${ }^{3}$. Por el contrario, y a diferencia de lo que había sucedido dos décadas antes con la Fábula de Andrómeda y Perseo ${ }^{4}$, no se incluyó en el manuscrito la música original de Juan Hidalgo, razón por la cual no se ha conservado como tal una partitura completa. Sin embargo, sin ninguna duda es la zarzuela de la que, al menos durante el primer cuarto de siglo de existencia del género, se conservan actualmente más fragmentos musicales.

Las composiciones pertenecientes a Los celos hacen estrellas publicadas por Jack Sage $e^{5}$ supusieron un hito -aunque no sin precedentes ${ }^{6}-\mathrm{y}$ abrieron una vía para la recuperación de un patrimonio musical depauperado y mayormente perdido: la música teatral de los Siglos de $\mathrm{Oro}^{7}$. A la zaga de su huella, ya sea en trabajos

\footnotetext{
${ }^{1}$ Todas las circunstancias relativas a la datación de la pieza y sus representaciones en el periodo de Carlos II pueden verse en Juan Vélez de Guevara: Los celos hacen estrellas, John E. Varey, Norman D. Shergold (eds.), con una edición y estudio de la música de Jack Sage, Londres, Tamesis Books, 1970, pp. xliv-liv. Probablemente tal referencia a una representación el año siguiente al estreno derive de un error de lectura, debiendo referirse a una década más tarde, o sea, 1683, que fue cuando verdaderamente tuvo lugar.

${ }^{2}$ Viena, Österreisiche Nationalbibliothek, Cod. Vindob. 13.217 (a partir de aquí, W). Además, del texto de la zarzuela hay una suelta, "Los zelos hacen estrellas y el amor hace prodigios, representación de dos jornadas de Don Juan Vélez de Guevara", impresa sin lugar ni año (pero probablemente en Madrid, en el año 1757) que a partir de ahora identificamos con la sigla $S$.

${ }^{3}$ Madrid, Archivo del Palacio Nacional [Archivo General de Palacio], Espectáculos públicos y privados, leg. 666: "A Juan de Calatayud, librero, por haber encuadernado cuatro comedias, a 12 reales cada una: 48 reales". Citado en J. Vélez de Guevara: Los celos hacen..., p. liii.

${ }^{4}$ Para la edición del manuscrito US-Hu Typ. 258H, véase Pedro Calderón de la Barca y Baccio del Bianco: Andrómeda y Perseo: fábula escénica, Rafael Maestre (ed.), Almagro, Museo Nacional del Teatro, 1994. Incluye apéndice facsimilar de la partitura musical (pp. 175-265).

${ }^{5}$ J. Vélez de Guevara: Los celos hacen..., pp. 243-273.

${ }^{6}$ Felipe Pedrell: Teatro lírico español anterior al siglo XIX, vols. IV-V, La Coruña, Canuto Berea y Compañía, 1898, pp xx-xxi, 13, 16-19. En concreto los tonos de la zarzuela incluidos por Pedrell son el solo "De las luces que en el mar", el dúo "Venid, venid, venid" y los cuatros "Celebren por las selvas", "Estrellas, luceros" y "Porque a pesar del recelo". (Además, incluye por error el solo de Minerva "Tonante dios", perteneciente realmente a La estatua de Prometeo, de Calderón de la Barca e Hidalgo). Después de Pedrell, el siguiente investigador que se interesó por la música de Los celos hacen estrellas fue el hispanista inglés J. B. Trend y, aunque no publicó el resultado de su investigación, John E. Varey y Norman D. Shergold nos dan particular cuenta de ella (Los celos hacen..., pp. xcvi-xcvii).

${ }^{7}$ Jack Sage: "La música de Juan Hidalgo para 'Los celos hacen estrellas' de Juan Vélez de Guevara", Los celos hacen estrellas, J. E. Varey, N. D. Shergold (eds.), Apéndice III (pp. 169-223) y edición de la música (pp. 243-273).
} 
específicos ${ }^{8}$ o más generales ${ }^{9}$, diversos investigadores han ido dando cuenta desde entonces de sus pesquisas y hallazgos, hasta el punto de localizar y recopilar casi por completo el total de fuentes musicales de la zarzuela de Vélez de Guevara e Hidalgo. Pero a este logro no solo han contribuido los tonos "humanos" y "de comediantes" actualmente conservados; también ha dado sus frutos la investigación de los repertorios de villancicos religiosos y de tonos "a lo divino" -y fundamentalmente aquellos vinculados al maestro de capilla de la catedral de Valladolid Miguel Gómez Camargo-, como pone de manifiesto su recopilación de ciertos tonos creados por Juan Hidalgo para la zarzuela de Vélez y su utilización de los mismos a la hora de componer sus villancicos, lo que una vez más pone de manifiesto la masiva circulación y pronta recepción de los repertorios vocales en España, y en este caso en particular, en dicha ciudad castellana.

En la presente ocasión en primer lugar me ocuparé someramente de las fuentes musicales más próximas al estreno de la zarzuela, conservadas actualmente en la Biblioteca Nacional de Madrid (completándolas con breves referencias a otros manuscritos que han contribuido, aunque de modo menos significativo, a la localización de obras relacionadas con la zarzuela) y en la segunda parte del artículo examinaré las fuentes vallisoletanas vinculadas a tal fábula escénica, tanto aquellos fragmentos con el texto "profano" original como los contrafacta atribuidos a Miguel Gómez Camargo, conservados todos ellos en su archivo, con especial atención al tono de Guerau, “iAlerta, que de los montes!” y al villancico de Gómez Camargo, ¡Alerta, que de los cielos!

\section{La música de Los celos hacen estrellas}

\section{Fuentes en la Biblioteca Nacional de Madrid}

Bartolomé José Gallardo, en el apéndice "Índice de Manuscritos de la Biblioteca Nacional" incluido en el segundo volumen de su Ensayo de una biblioteca española de libros raros y curiosos, meramente se limita a citar a Juan

\footnotetext{
${ }^{8}$ Carmelo Caballero: "Nuevas fuentes musicales de 'Los celos hacen estrellas', de Juan Vélez de Guevara", Cuadernos de Teatro Clásico, 3, 1989, pp. 119-155.

${ }^{9}$ Louise K. Stein: Songs of Mortals, Dialogues of the Gods. Music and Theatre in Seventeenth-Century Spain, Oxford, Clarendon Press, 1993; June Yakeley: "New Sources of Spanish Music for the Five-Course Guitar", Revista de Musicología, 19, 1-2 (1996), pp. 267-286; Álvaro Torrente, Pablo-Luis Rodríguez: "The 'Guerra Manuscript"', Journal of the Royal Musical Association, 123, 2, 1998, 147-189; John Koegel: "New Sources of Music from Spain and Colonial Mexico at the Sutro Library", Notes, 55, 3, 1999, pp. 583-613; Lola Josa, Mariano Lambea: "Tonos humanos teatrales en el Cancionero Poético-Musical de Mallorca (CPMM) (finales del siglo XVII-principios del siglo XVIII)", Rumbos del hispanismo en el umbral del Cincuentenario de la AIH, IV. Teatro, Debora Vaccari (ed.), Roma, Bagatto Libri, 2012, pp. 143-151. Resulta cuando menos llamativo que estos mismos autores no hayan incluido ninguna pieza ni referencia alguna a los tonos de Juan Hidalgo para Los celos hacen estrellas en su reciente edición, Lola Josa, Mariano Lambea (eds.): Juan Hidalgo (1614-1685): Tonos y villancicos, Madrid, Dairea Ediciones, 2017.
} 
Hidalgo respecto a un legajo de Tonadillas puestas en música, con la signatura Aa. $211^{10}$. No describió la tipología de las fuentes que incluía ni tampoco desglosó sus contenidos. La información proporcionada por Felipe Pedrell tras su consulta y transcripción parcial tampoco fue exhaustiva, limitándose a afirmar que en el citado legajo "No toda la música de Hidalgo es de Hidalgo (tonadas, dúos y música de comedias y zarzuelas), sino de otros autores, profanos y religiosos, como Patiño, Garay, Torre (Jerónimo de la), Marín, etc." ${ }^{11}$. Así pues, hasta la publicación del primer volumen del catálogo de los fondos musicales de la Biblioteca Nacional de Anglés y Subirá no se supo de forma detallada qué tonos incluían las cajas que conformaban el citado volumen de Tonadillas de Hidalgo ${ }^{12}$ y hoy día seguimos sin saber nada sobre el origen y formación de este legajo constituido por varios tonos manuscritos a solo, a dúo y a cuatro, predominantemente "humanos" - desconocemos de dónde proceden los juegos de partichelas, cuándo pasaron a engrosar los fondos de la Biblioteca Nacional, si fueron legados (y por quién) o comprados, si formaban ya un conjunto homogéneo en el momento de su adquisición o son fruto de diversos aportes a lo largo del tiempo-. Sin embargo, creo poder afirmar, por una parte, que Gallardo y Pedrell se referían por el nombre de Tonadillas de Hidalgo al contenido global de las actuales cajas MC/3880, MC/3881 y MC/5001/13 (así pues, dicho legajo de Tonadillas de Hidalgo debió ser desmembrado y reorganizado en las primeras décadas del siglo XX, después de ser consultado por Pedrell, pero antes de ser catalogado por Higinio Anglés y José Subirá) y por otra, que las obras pertenecientes a la zarzuela de Vélez de Guevara e Hidalgo Los celos hacen estrellas desde el primer momento formaron una parte esencial del mismo. No obstante, parece evidente que el anónimo organizador de los contenidos de las nuevas cajas no tuvo en consideración -o solo la tuvo parcialmente- que varios de los tonos pertenecían a dicha zarzuela; si hubiera sido de otro modo, éstos se habrían in-

${ }^{10}$ Bartolomé José Gallardo: Ensayo de una biblioteca española de libros raros y curiosos, tomo II, Madrid, Rivadeneyra, 1866, p. 74a.

${ }^{11}$ Felipe Pedrell: Teatro lírico español anterior al siglo XIX, vol. III, La Coruña, Canuto Berea y Compañía, 1897, p. xxx.

${ }^{12}$ Higinio Anglés, José Subirá: Catálogo musical de la Biblioteca Nacional de Madrid, Barcelona, Consejo Superior de Investigaciones Científicas, Instituto Español de Musicología, 1946-1951, 3 vols. El catálogo de los 57 tonos que contiene MC/3880 aparece en el primer volumen, entrada n. ${ }^{\circ} 137$, pp. 274-280, y los 55 tonos de MC/3881 se describen en el n. ${ }^{\circ}$ 138, pp. 280-290. La caja MC/5001 fue descubierta muy recientemente y, por lo tanto, no está descrita en el Catálogo de Anglés / Subirá.

${ }^{13}$ De los autores citados por Pedrell solo encontramos actualmente obras de Jerónimo de Latorre en papeles sueltos en la caja MC/5001 $(16,17)$; por otra parte, hay tonos de Carlos Patiño en MC/3881 (23, $24,55)$ y MC/5001 (24) y de José Marín, los hay tanto en esta como en la MC/3880. Sin embargo, en ninguna de las tres carpetas encontramos tonos de Garay (quizá Pedrell recordaba el tono En peso la noche toda, de Garay presente en E-Mn Mss/13622, Música vocal antigua, de la misma institución), aunque es posible que se trate de un error y el musicólogo catalán se refiriese más bien a Garau (vide infra). 
corporado a su nueva ubicación (presumiblemente la caja MC/3880) en una secuencia lógica -ya fuera siguiendo el orden en que aparecen las intervenciones musicales en el texto dramático o ya en el que se deduce de la antigua numeración que aparece en dichos juegos de partichelas-, pero muy al contrario, los tonos pertenecientes a Los celos hacen estrellas se incorporaron "barajados" y dispersos.

Todo invita a pensar que la música de Los celos hacen estrellas, a pesar de estar dividida en veintiséis carpetillas con partichelas independientes, debió trasmitirse originalmente de forma conjunta, como un todo (como un "atado", aunque cada una de las obras, a excepción del cuatro inicial de la loa, fueran numeradas independientemente). Sin embargo, ya cuando el contenido de Tonadillas de Hidalgo fue dividido en cajas (y probablemente antes, ya cuando lo consultaron Gallardo y Pedrell) algunas de las piezas que formaban parte de ese hipotético "atado" se habían extraviado, como puede deducirse de la comparación entre el texto de Juan Vélez y los fragmentos musicales de la zarzuela, o simplemente al constatar las discontinuidades de la numeración antigua en dichos tonos conservados en la caja $\mathrm{MC} / 3880$. A ese núcleo de composiciones destinadas a Los celos hacen estrellas que formó la base de MC/3880 se añadieron e incorporaron otros tonos "a lo divino" y "a lo humano" de diversos autores, algunos relacionados con otras producciones teatrales más o menos coetáneas o próximas en el tiempo. Como ya hemos sugerido, podemos diferenciar las obras pertenecientes a Los celos hacen estrellas del resto de composiciones que aparecen en las cajas MC/3880, MC/3881 y MC/5001 debido a que los fragmentos pertenecientes a dicha zarzuela presentan una numeración antigua, anotada por mano del copista principal, que sigue la secuencia propia y lógica en el discurrir de la obra teatral. El resto de las composiciones incluidas en el legajo Tonadillas de Hidalgo, ya fueran destinadas al teatro o no, carecen de signatura ordinal antigua alguna. Por otra parte, todos los fragmentos musicales de la Biblioteca Nacional vinculados a la zarzuela se concentran casi exclusivamente en la caja $\mathrm{MC} / 3880 /{ }^{14}$.

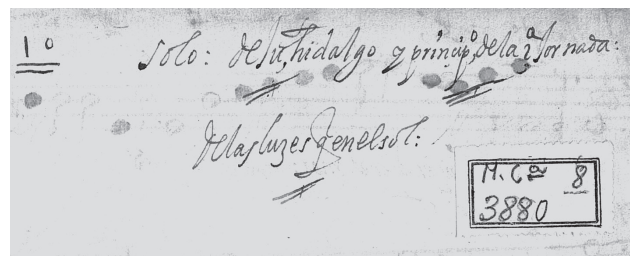

Ilustración 1. Portadilla de E-Mn MC/3880/8, De las luces que en el sol [sic] de Juan Hidalgo (fragmento)

\footnotetext{
${ }^{14}$ Aparte de los fragmentos localizados en la caja MC/3880, solamente encontramos el tono a solo de tiple y acompañamiento Si los celos se hallan en E-Mn Mss/13622, p. 27.
} 
En la ilustración 1 puede verse a simple vista cómo diferenciar los tonos pertenecientes a la zarzuela Los celos hacen estrellas del resto, ya que aquellos presentan, en el reverso de la parte de acompañamiento, además de la signatura actual (en este ejemplo, "M/CA/3880") y el primer verso de la canción ("De las luzes que en el sol [sic]") comunes a todas las fuentes, al menos alguna (si no todas) de las siguientes particularidades en sus portadas: a) el número de voces y el nombre del compositor ("Solo: de Ju. Hidalgo"), b) el momento en el que había de cantarse ese tal en el discurrir de la zarzuela ("prinçipio de la $2^{\mathrm{a}}$ jornada") o bien, en otros casos, las dramatis personae intervinientes (Amor y Mercurio, Diosas, Labradoras), y c) por último, pero indudablemente lo más importante, un número ("10") anotado por el copista original que corresponde al orden que ocupaba dicha composición dentro de la secuencia de intervenciones musicales en la zarzuela; las otras composiciones que pertenecían al legajo Tonadillas de Hidalgo no presentan nunca esta particular numeración ${ }^{15}$.

Si establecemos una comparación entre las intervenciones musicales que prescribe el manuscrito teatral $W$ y los fragmentos musicales que se han conservado principalmente en la Biblioteca Nacional de Madrid podemos concluir que la música de la loa se conserva completa, aunque sigue resultando inexplicable el orden de las piezas que demanda la numeración antigua ${ }^{16}$. La loa prescribe el mismo fragmento polifónico entonado por la Música a cuatro voces al principio $\mathrm{y}$ al final de la misma, cuatro que enmarca tres diferentes tonadas a solo y acompañamiento cantadas respectivamente por Bernarda, Borja y Manuela ${ }^{17}$; en los juegos de partichelas de la zarzuela, la pieza inicial no lleva ordinal alguno en la numeración antigua, quizá debido a que la rúbrica que añadió el copista no

${ }^{15}$ En algunas piezas ese número de orden antiguo no aparece, o no coincide con el orden que lleva la pieza en la zarzuela, generalmente debido a que se trata de copias efectuadas no por el copista original, sino por otra mano presumiblemente posterior. Tampoco lleva numeración el cuatro inicial de la loa, en este caso quizá porque la rúbrica "A 4 y principio de la loa" que aparece en la portada resultaba suficientemente elocuente y no precisaba de mayor concreción.

${ }^{16}$ En el cuadro del apéndice 1 pueden verse enfrentadas las referencias de los fragmentos musicales en la zarzuela, incluida la loa y el fin de fiesta, y las signaturas de los tonos efectivamente conservados. La primera columna presenta el orden de las diversas secciones ( $\mathrm{L}=\mathrm{Loa}$; I = Primer Acto; II = Segundo Acto; $\mathrm{F}=$ Fin de fiesta) seguido de un número arábigo que indica su posición dentro de cada una de ellas en el texto dramático; la segunda columna presenta la antigua numeración de las piezas en MC/3880: en texto normal las conservadas; entre corchetes angulares, las localizadas en otros manuscritos; entre corchetes normales, las perdidas; entre paréntesis, las repetidas, y entre llaves, los casos especiales; la tercera columna presenta los incipits literarios de cada uno de los fragmentos cantados: en cursiva, la primera sección; las demás, en texto normal; en la cuarta columna las referencias sin sangrar dan cuenta aquellos tonos localizados en E-Mn MC/3880; en cursivas y sin sangrar, los hallados en otros manuscritos de E-Mn, y en texto normal y sangrado los procedentes de otras bibliotecas y archivos.

${ }^{17}$ Estos son los nombres reales de las actrices que participaron en el estreno de la zarzuela en 1672. Las referencias a los actores en la loa fueron los datos fundamentales utilizados por Varey y Shergold para determinar la fecha de estreno de la obra, atendiendo precisamente a su ausencia o presencia en la corte. Véase J. Vélez de Guevara: Los celos hacen..., pp. xlix-1. 
dejaba lugar a dudas sobre su posición capital:"A 4 y principio de la loa / A los floridos años"18. La tonada a solo "De los ceños de diciembre", a pesar de su actual localización, lleva el ordinal antiguo " 1 ", dado que la primera jornada de la zarzuela, la cual sigue a la loa, comienza con la "tercera obra: Celebren por las selvas", parece deducirse de la numeración antigua que únicamente se cantó una tonada más en la primera sección, pero tanto $W$ como $S$ prescriben dos solos más:"Peinándose estaba un olmo"y "¿Cómo ha de saber Belilla?". Las dos se conservan en $\mathrm{MC} / 3880$, pero ninguna de ellas lleva el ordinal antiguo " 2 " ' ¿Cómo encarar los problemas derivados de esta situación? Es claro que solo una de estas dos tonadas pudo haber llevado el ordinal "2". Creemos que, probablemente el copista otorgó tal número en un primer momento y de manera inadvertida a “¿Cómo ha de saber Belilla?" pero al repasar su trabajo, confrontarlo con el texto dramático y percatarse de que había olvidado copiar en el lugar correcto el tono "Peinándose estaba un olmo", colocó este al final de toda la música de la zarzuela incluso después del tono del Fin de Fiesta, "Barajábalas Amor"- asignándole el postrer número de la serie, el 25. De este modo, los solos de la loa en el orden correcto llevarían en la portada los números 1,25 y 2.

Un problema más deriva del hecho de la ausencia del número " 2 " en la copia conservada actualmente en E-Mn MC/3880/42 de "¿Cómo ha de saber Belilla?", ausencia que se debe, sin duda, al hecho de que la copia conservada actualmente no fue anotada por el copista principal, sino por uno diferente (y probablemente posterior), con otra caligrafia y otros usos de escritura que no incluían la indexación de las piezas ${ }^{19}$.

No resultaría extraño, a mi juicio, que la loa hubiera sido la sección que se escribió y compuso más tarde. Quizá Hidalgo, al encargársele la composición de la música de la zarzuela recibió con antelación una copia del texto de la misma a excepción de la loa, quizá solamente esbozada y sin acabar, advirtiéndole simplemente con una indicación verbal o similar de que para la loa debía componer un cuatro inicial y dos solos ${ }^{20}$. Con vistas a su inminente representación Juan Vélez habría completado la loa con una ampliación que incluía una nueva intervención musical más, “CCómo ha de saber Belilla?”, pasando así de necesitar dos solos a precisar tres, todo lo cual es compatible con lo apuntado en el párrafo anterior. En cualquier caso, se trata de una mera hipótesis, ya que, dado el actual estado de cosas, no creo que haya una explicación enteramente satisfactoria sobre el proceso de copia de la música de la loa.

\footnotetext{
${ }^{18}$ En el cuadro del apéndice 1 le hemos otorgado a esa obra polifónica la letra alpha $(\alpha)$.

${ }^{19}$ También es posible que este segundo copista desconociera la pertenencia de la tonada "¿Cómo ha de saber Belilla?" a Los celos hacen estrellas, ya que el resto de las obras copiadas por él que se conservan en las cajas de la Biblioteca Nacional aparecen como "tonos humanos", sin aparente vinculación teatral.

${ }^{20}$ A este respecto, los tonos "De los ceños de diciembre" y "Peinándose estaba un olmo" están estrechamente imbricados desde un punto de vista argumental -al invierno sigue la primavera- y el menos justificable en este sentido es “¿Cómo ha de saber Belilla?”, lo que lo haría más proclive a ser el añadido en última instancia.
} 
Por lo que respecta a la música de la primera jornada de la zarzuela, en la Biblioteca Nacional se conservan aparentemente todos los fragmentos, a excepción del solo de Amor, "Recelos cuidados"21 - cuya portada debía llevar el número "6"-,y el tono final de Mercurio,"No, no se asegure", que debía llevar el número "9"22. Así pues, en las piezas pertenecientes a la primera jornada la numeración antigua que figura en las carpetillas es coherente con el discurrir de la zarzuela (aunque su colocación actual en la caja MC/3880 lo sea solo parcialmente).

Sin embargo, una mirada más atenta a las fuentes de la " 8 " pieza atestigua ciertas particularidades que merecen ser comentadas pormenorizadamente. La portada de la fuente musical E-Mn MC/3880/5 lleva la rúbrica "Humano. Alerta, que de los montes. Garau" -siendo este un joven contralto mallorquín al servicio de la Real Capilla en el momento del estreno de la zarzuela ${ }^{23}$ - de modo que no vincula su contenido a Los celos hacen estrellas ni tampoco su pertenencia a obra escénica alguna, calificándolo solo como un tono humano; además, tal pieza fue anotada por un copista diferente al del resto de las fuentes de la zarzuela; por último, carece de la signatura ordinal que se halla habitualmente en las obras pertenecientes a tal fábula escénica. Por otra parte, no parece probable que un joven e inexperto cantor colaborara con el mejor compositor de tonos de la época en un proyecto tan importante como una fiesta teatral destinada a celebrar a un miembro de la real familia.

De mayor interés resultan las cuestiones relativas a la composición propiamente dicha. Al confrontar el texto de la zarzuela con el del tono compuesto por Guerau advertimos que únicamente coinciden las coplas, mientras que el estribillo es completamente diferente en ambas fuentes. Estos son:

Que baja, que cubre de rayos las selvas de asombros las luces.
El diciembre se acerca

y el mayo huye.

Flores, jalerta, alerta!, que se destruye de los campos lo verde, del sol las luces.

(W, vv. 986-1044)

(E-Mn MC/3880/5)

${ }^{21}$ Aunque no se ha conservado en la Biblioteca Nacional, esta tonada se encuentra en E-V 85/32; E-V 84/257 y E-SCu MS 265, ff. 17v-18.

${ }^{22}$ Las similitudes métricas con el estribillo del tono "Alerta que de los montes", hacen bastante plausible su reconstrucción a partir de la sección "Que baja, que cubre" de la obra citada.

${ }^{23}$ Sobre la trayectoria de Francisco Guerau en Madrid véase Gerardo Arriaga: "Francisco y Gabriel Guerau, músicos mallorquines", Revista de Musicología, 7, 2, 1984, pp. 253-299. En 1672 F. Guerau debía de tener 23 años y solo llevaba tres años de cantor en la Real Capilla. Pedrell lo consignó en su introducción al vol. III del Teatro lírico como Garay, posiblemente por error de lectura o copia, dado que, como ya he apuntado, no hay ningún Garay ni en MC/3880 ni tampoco en las cajas MC/3881 y MC/5001. 
Debemos suponer, pues, que el tono humano "iAlerta, que de los montes!" de Francisco Guerau en realidad no corresponde propiamente a Los celos hacen estrellas. Parece ser, pues, que el mallorquín no colaboró con esta pieza en la composición original de la música de la zarzuela, sino que únicamente tomó prestado de la misma el romance inicial de este fragmento -al menos su texto, pues no sabemos si la música que figura en E-Mn MC/3880/5 es original del cantor mallorquín o si, por el contrario, corresponde al romance supuestamente compuesto por Juan Hidalgo, hoy día perdido- y vinculó dicho romance a un estribillo de nueva factura. Dado que los textos de ambos estribillos son métrica y acentualmente tan distintos entre sí, lo lógico es pensar que, al menos en esta sección, la música de Guerau es completamente diferente a la de Hidalgo. (Sobre los aspectos musicales de esta pieza comentaré mis conclusiones en la segunda parte de este trabajo a la luz de un contrafactum recientemente localizado).

Por último, el tono cantado por Mercurio al final de la primera jornada, "No, no se asegure", es muy probable que tuviera la signatura ordinal "9o" en la fuente original, actualmente en paradero desconocido. No obstante, las similitudes poéticas (metro y rima) con el estribillo de la canción anterior -“¡No, no se asegure / desvelo que guarda / de engaño que burle!"- hacen plausible su reconstrucción a partir de tal tono.

Por lo que respecta a los fragmentos pertenecientes a la segunda jornada, las pérdidas de las carpetillas originales de la Biblioteca Nacional son más acusadas, aunque casi todas las composiciones faltantes han podido ser recuperadas a partir de las concordancias localizadas en otros archivos y bibliotecas ${ }^{24}$. En concreto se extraviaron cinco tonos -“"Ay, cómo gime!", "Al aire se entregue”, "Si los celos se hallan", "Con la pasión amorosa” y "iAh de las montañas de Argos!"- que conforman la música de la parte central de la jornada y que debían llevar en las correspondientes portadillas de sus juegos de partichelas los números originales correlativos 14 al 18. Adviértase que las actuales signaturas otorgadas por los facultativos de la Biblioteca Nacional a los fragmentos musicales de esta jornada siguen, a partir del tono II.2, la secuencia lógica del texto de la zarzuela, toda vez asumida la pérdida de las piezas antes citadas, tal como expresan los guarismos finales de las signaturas (E-Mn MC/3880/12 a $\mathrm{MC} / 3880 / 18$ ), lo cual apunta a que cuando se organizó la caja MC/3880 tales piezas ya se habían extraviado.

En los fragmentos musicales del final del segundo acto se presentan inconsistencias e irregularidades para las que no encuentro una explicación totalmente satisfactoria a día de hoy. En primer lugar, no se conserva el tono 21 de

${ }^{24}$ En este sentido las fuentes recuperadas se localizan preferentemente en el archivo musical de la catedral de Valladolid (E-V) y en la Biblioteca Xeral de la Universidad de Santiago de Compostela (E-SCu). A este respecto véase el Apéndice 1. 
la serie, pero tampoco logramos percibir con claridad en el texto de la zarzuela el fragmento al que correspondería tal pieza perdida, pues no hay solución de continuidad entre el cuatro n. ${ }^{\circ} 20$, "Estrellas, luceros..." y el dúo de Amor y Mercurio "Venid, venid a este sitio", que tiene asignado el n. ${ }^{\circ} 22$ por el copista. Es posible que el cuatro "Dioses, ya vienen las selvas"-que solo aparece en la fuente $S$, pero no en la original $W$ - fuera el fragmento destinado a llevar el vigésimo primer número de la serie ${ }^{25}$.

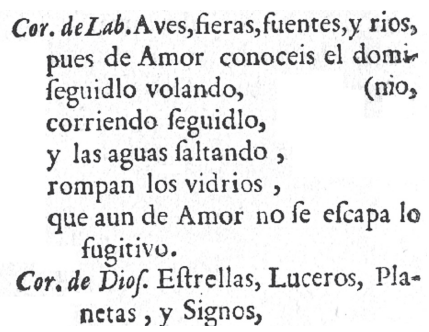

\author{
pues deAmor conoceis el dominio, \\ dorando, influyendo \\ pefares, y alivios, \\ los Cielos difculpen \\ amantes delitos, \\ que aun de amor no fe efcapa lo \\ cryftalino. \\ Merc.y $A m$. Venid,venid à efte fitio, \\ donde de amor, $y$ poder \\ vercis el poder unido. \\ Lab. Que aun de amor, \&c. \\ Diof. Quie aun de amor, \&ce. \\ Zab. Diofes, yà vienen las felvas \\ à vér en efte diftrito, \\ que hing el amor maridage \\ de efmeraldas, y zafíros. \\ Cor.deDiof.Selvas, yà baxan los Diofes \\ á vèr con difcreto a rbitrio, \\ que haga el amor en los zelos, \\ conformidad lo difinto. \\ Merc.y Am. Venid, venid á efte fitio, \\ donde de amor, $y$ poder, \\ vereis el poder unido. Salen tod.
}

Ilustración 2. Los celos hacen estrellas según S, pp. 41 col. b-42, col. a

Además, en la numeración de los tonos en la caja MC/3880 figura, con el n. ' 24, "Trompicábalas Amor" (aunque con la variante significativa y muy acertada, a mi juicio, "Barajábalas Amor"), que aparece en el fin de fiesta del Maulero que busca la mojiganga, del propio Juan Vélez, que figura como colofón de la fiesta teatral solo en $W$. Por último, la postrera carpetilla con numeración antigua (n. $\left.{ }^{\circ} 25\right)$ corresponde, como he apuntado anteriormente, al tono de la loa "Peinándose estaba un olmo", del que ya hice las oportunas apreciaciones.

\footnotetext{
${ }^{25}$ Solo la consideración de un error cometido por el copista en la numeración original daría lugar a una explicación satisfactoria, a saber: el dúo de Amor y Mercurio "Venid, venid a este sitio" (n. ${ }^{\circ} 22$ ) debería llevar el número 21; así, el 22 podría corresponder al cuatro de Labradoras "Dioses, ya vienen las selvas" y al Coro de Diosas "Selvas, ya bajan los dioses", coros que no se han conservado. Apuntemos que estas dos últimas cuartetas se adecúan perfectamente a la música del n. ${ }^{\circ} 23$ que pone fin al segundo acto, "Porque a pesar del recelo". Esta solución de tal anomalía es hipotética y dista mucho de ser convincente.
} 


\section{Otras fuentes manuscritas con tonos de Los celos hacen estrellas ${ }^{26}$}

Después de la composición y estreno (el 22 de diciembre del 1672) de la zarzuela Los celos hacen estrellas -del que quizá sean descendientes directos los tonos conservados en la caja MC/3880 de la Biblioteca Nacional de Madridse produjo la inmediata difusión de algunos de los más importantes tonos de dicha obra dramática, con la particularidad de que aparentemente solo circularon aquellas tonadas a solo y acompañamiento con estructura biseccional ('estribillo más coplas' o 'romance con estribillo'), excepto la alirada "La noche tenebrosa". Una serie de manuscritos conservados hoy día en diversos archivos y bibliotecas atestigua la rápida circulación y propagación de dichos tonos. En primer lugar, el E-SCu MS 265 (manuscrito Guerra) es una antología de canciones solísticas españolas de ca. $1680^{27}$ que incluyó entre sus diversos contenidos todos los tonos a solo biseccionales de la zarzuela excepto los siguientes: "Peinándose estaba un olmo”, de la loa; “Al poderoso ruego” y “iAlerta, que de los montes!", de la primera jornada, y “iAy cómo gime!”, de la segunda. Precisamente dado el carácter solista de la colección, en la fuente compostelana no figura ninguna de las piezas polifónicas de la zarzuela original, pero tampoco las tonadas estróficas del primer acto "¿Quién a las puertas de Marte?” y "Juno, que del dios supremo"; además, no figura el final del primer acto, "No, no se asegure", ni las seguidillas "Sepan todos que Juno", del segundo.

Dentro de los variopintos contenidos del manuscrito Guerra, los tonos de Los celos hacen estrellas no presentan vínculo alguno entre sí que nos sugiera que todos ellos formaban parte originalmente de una entidad o un producto mayor, un manuscrito musical completo de la citada obra dramática. Es decir, fueron incluidos no como canciones teatrales de una obra escénica determinada, sino en calidad de "tonos humanos" independientes, ajenos a su origen teatral, como tantos otros tonos contemporáneos.

Además encontramos otros tonos pertenecientes a la zarzuela en cantidad mucho menos significativa en otras colecciones antológicas manuscritas de tonos humanos que proliferaron a lo largo del último cuarto del siglo XVII y de la primera década de la siguiente centuria tanto en España como en América, como son el manuscrito Gayangos-Barbieri ${ }^{28}$, el Cancionero Poético

${ }^{26}$ En el cuadro del apéndice 1 pueden consultarse todas las concordancias musicales localizadas hasta la fecha de los tonos de Los celos hacen estrellas; en dicho cuadro he omitido las concordancias puramente literarias, que, por supuesto, también existen.

${ }^{27}$ Descrito en Álvaro Torrente, Pablo-L. Rodríguez: "The 'Guerra Manuscript' (c. 1680) and the Rise of Solo Song in Spain", Journal of the Royal Musical Association, 123, 2, 1998, pp. 147-189. A diferencia de las piezas de la caja MC/3880 de la Biblioteca Nacional, este manuscrito está encuadernado y no fue particularmente diseñado para la interpretación musical de sus contenidos.

${ }^{28}$ E-Mn Mss/13622, descrito en Carmelo Caballero: "El manuscrito Gayangos-Barbieri", Revista de Musicología, 12, 1989, pp. 199-268; en el f. 27 se localiza el tono Si los celos se hallan. 
Musical de Mallorca ${ }^{29}$, el I-Vnm MS Italiani, 4/470 de la Biblioteca Marciana de Venecia ${ }^{30}$ y el US-SFs SMMS M1 ${ }^{31}$, todos ellos tipológicamente similares al manuscrito Guerra, esto es, manuscritos recopilatorios de composiciones de diverso origen no necesariamente destinados a la interpretación, sino más bien recopilaciones de coleccionista experto o piezas destinadas al aprendizaje y estudio.

Hay un grupo más de fuentes manuscritas -y quizá desde cierto punto de vista el más importante de todos- que participa en parte de ese afán colector, pero el impulso recopilatorio en este caso se debió no a un acaudalado mecenas, a alguna personalidad señalada en el mundo de las letras o de la escena española o a algún intérprete en busca de repertorio para cantar, sino al maestro de capilla de la catedral de Valladolid, Miguel Gómez Camargo ${ }^{32}$. Tras su muerte, además de las composiciones litúrgicas y paralitúrgicas propias de su oficio tanto de latín (misas, motetes, salves, etc.) como de "romance" (villancicos a todo tipo de advocaciones) pasaron a engrosar los fondos del archivo musical de la catedral de Valladolid numerosos papeles sueltos poéticos y musicales entre los cuales se conservan decenas de tonos "a lo divino" y "a lo humano", así como diferentes fragmentos de música teatral de diversos autores coetáneos del compositor. En algunos casos podemos suponer que los tonos humanos y "de comediantes" le fueron remitidos principalmente desde Madrid, centro productor por antonomasia de tales repertorios; en el caso concreto de los tonos de la zarzuela que nos ocupa no creemos que circularan y que llegaran a manos del maestro de capilla como un conjunto completo y homogéneo, con un único origen y en el mismo momento, dado que aparecen anotados por distintos copistas y en diferentes formatos. Son fuentes, en suma, aparentemente no relacionadas entre sí, seguramente proporcionadas por diversos músicos o representantes activos en la corte, pues los tonos aparecen copiados por amanuenses ajenos a la catedral y desconocidos en el ámbito vallisoletano ${ }^{33}$, como muestran las siguientes imágenes (ilustraciones 3 y 4 ):

\footnotetext{
${ }^{29}$ E-Bc M 3660, descrito en J. Yakeley: "New Sources of Spanish...”, pp. 279-280; bajo la rúbrica de "solo humano" incluye exclusivamente el tono de la zarzuela Al aire se entregue / En este nuevo alentar, en ff. $22 \mathrm{v}-23 \mathrm{v}$.

${ }^{30}$ I-Vnm MS Italiani, 4/470, descrito en Taddeo Wiel: I codici musicali Contariniani del secolo XVII nella R. Biblioteca di san Marco in Venezia, Venezia, 1888; en los ff. 82-86 incluye el tono Si los celos se hallan.

${ }^{31}$ John Koegel: "New Sources of Music...", pp. 583-613; "De los ceños de diciembre", f. 8.

32 Gran parte de las referencias de archivo sobre los fondos musicales vallisoletanos y la producción musical de Miguel Gómez Camargo -aunque no todas- están tomadas de José López-Calo: La Música en la Catedral de Valladolid. Catálogo del Archivo de Música, Valladolid, Ayuntamiento de Valladolid, 2007, 7 vols.

${ }^{33}$ Tenemos constancia de que a mediados de la década de 1670 Miguel Gómez Camargo tenía relación -ya fuera directa o ya por persona interpuesta- con algunos comediantes activos en la corte, como Alonso de Olmedo (a través de Cristóbal Galán, maestro de capilla de las Descalzas en 1672), quien participó en el estreno de Los celos hacen estrellas, o el autor de comedias Manuel Vallejo (en 1674, según nos informa Lorenzo de Urruela en su correspondencia con el maestro de capilla de Valladolid). Véase Carmelo Caballero Fernández-
} 


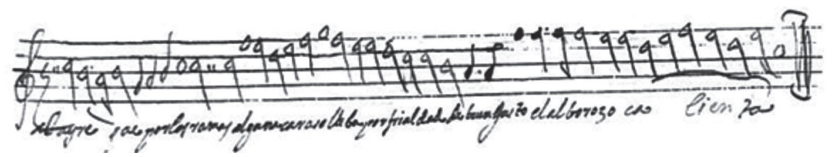

Ilustración 3. E-V 85/32, [Coplas]: Al aire que por las ramas. Copista desconocido

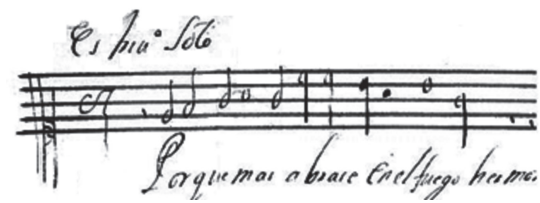

Ilustración 4. E-V 84/239, Estribillo Solo: Porque más abrase. Copista desconocido

Por el contrario, en otros casos los tonos de la zarzuela de Juan Vélez de Guevara y Juan Hidalgo aparecen copiados por el propio maestro de capilla bien en papeles sueltos (ilustración 5) o bien en sus propios Borradores de Villancicos (ilustración 6), según delata su peculiar caligrafia.

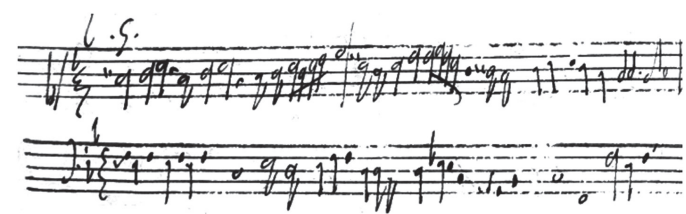

Ilustración 5. E-V 84/257, [Recelos, cuidados]. Copia de Miguel Gómez Camargo

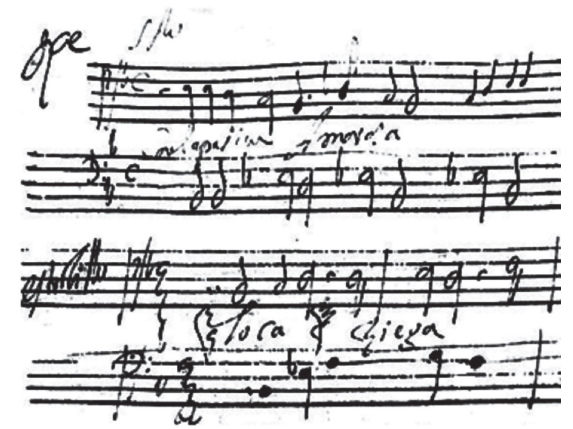

Ilustración 6. E-V 71/23,f.10v, Romance: Con la pasión amorosa; Estribillo: "Que loca, que ciega" [fragmento]. Copia de M. Gómez Camargo

Rufete: "En el bufete de Miguel Gómez Camargo. Circulación de repertorios poético-musicales en España en la segunda mitad del siglo XVII", Ámbitos artísticos y literarios de sociabilidad en los Siglos de Oro, Elena Martínez Carro, Alejandra Ulla Lorenzo (eds.), Kassel, Reichenberger, 2020, pp. 121-138. 
Aunque no todas las copias de las tonadas de la zarzuela localizadas en el archivo catedralicio vallisoletano son susceptibles de ser fechadas, aquellos casos en los que podemos establecer una datación precisa revelan que el proceso de circulación respecto al momento del estreno de la obra fue casi inmediato, sin tiempo apenas para que tales melodías se hubieran divulgado y popularizado en exceso. Es probable, pues, que fueran buscadas y coleccionadas ansiosamente por Miguel Gómez Camargo más que como composiciones muy conocidas y apreciadas por un público masivo (o como mínimo amplio), como obras de nueva creación de un reputado y encumbrado compositor de corte que podrían contribuir a aliviar, mediante el procedimiento del contrafactum, su ingente y siempre extenuante obligación de componer un número considerablemente elevado de villancicos cada año (sin desdeñar la posibilidad de que a la vez tratara de suplir cierta "aridez" o "inseguridad" melódica como compositor).

\section{Las fuentes musicales "a lo divino" de Los celos hacen estrellas en la Catedral de Valladolid}

Pero la finalidad con la que Camargo recopiló y copió diversos tonos de Los celos hacen estrellas (y de muchas más obras "humanas", escénicas o no) no era puramente coleccionista, sino que utilizaba dichas melodías como punto de partida para la elaboración de diferentes "villancicos sobre la tonada" 34 a diversas advocaciones, y en el caso concreto que nos ocupa, particularmente para los maitines al Nacimiento de los años 1674 y 1675, para la festividad del Corpus Christi de 1674 y "para la festividad del Nombre de María" (después de 1674), y "también este billanzico es para alguna festividad de Nuestra Señora" ${ }^{35}$.Todos ellos se recogen en el siguiente cuadro de fuentes "a lo divino" de tonos de Los celos hacen estrellas.

Antes de pasar adelante recordemos que el villancico "sobre la tonada" es la tipología más frecuente dentro de los diversos procedimientos de divinización que encontramos en el repertorio religioso en romance de la segunda mitad del siglo XVII y consiste, básicamente, en presentar el estribillo articulado en dos secciones diversas: en la primera se canta la melodía original tomada en préstamo sin modificación musical sustantiva alguna, pero dotándola de un nuevo texto de carácter religioso; la segunda, denominada frecuentemente responsión, es una sección polifónica, y muy a menudo policoral, en donde el maestro de capilla utiliza la

\footnotetext{
${ }^{34}$ Sobre los villancicos "sobre la tonada" en general véase Carmelo Caballero Fernández-Rufete: "Miscent sacra profanis: música profana y teatral en los villancicos de la segunda mitad del siglo XVII", Música y literatura en la Península Ibérica: 1600-1750. Actas del Congreso Internacional, Valladolid, 20-21 y 22 de febrero, 1995, Valladolid, Sociedad "V Centenario del Tratado de Tordesillas" / Universidad de Valladolid, 1997, pp. 151-167.

${ }^{35}$ Las rúbricas marianas aparecen en la partichela de acompañamiento al arpa del correspondiente juego, E-V 62/77, que se encuentra desgajada de su cuadernillo y se incorporó a una de las carpetas de Papeles sueltos, E-V 84/240.
} 
melodía en préstamo recién escuchada y la manipula para desarrollarla, amplificarla y ornamentarla de muy diverso modo, introduciendo texturas, tímbricas, modulaciones y desarrollos de su propia cosecha. Por otra parte, en las coplas se comporta como en la primera presentación del estribillo, es decir, por lo general son musicalmente idénticas a las originales profanas, cambiando solo el elemento literario para "divinizarlo". Es importante subrayar que, desde un punto de vista únicamente musical, al cantar estos villancicos la música de las tonadas teatrales es plenamente reconocible, no aparece desestructurada ni "enmascarada".

Cuadro 1. Villancicos "sobre la tonada" en E-V relacionados con Los celos hacen estrellas

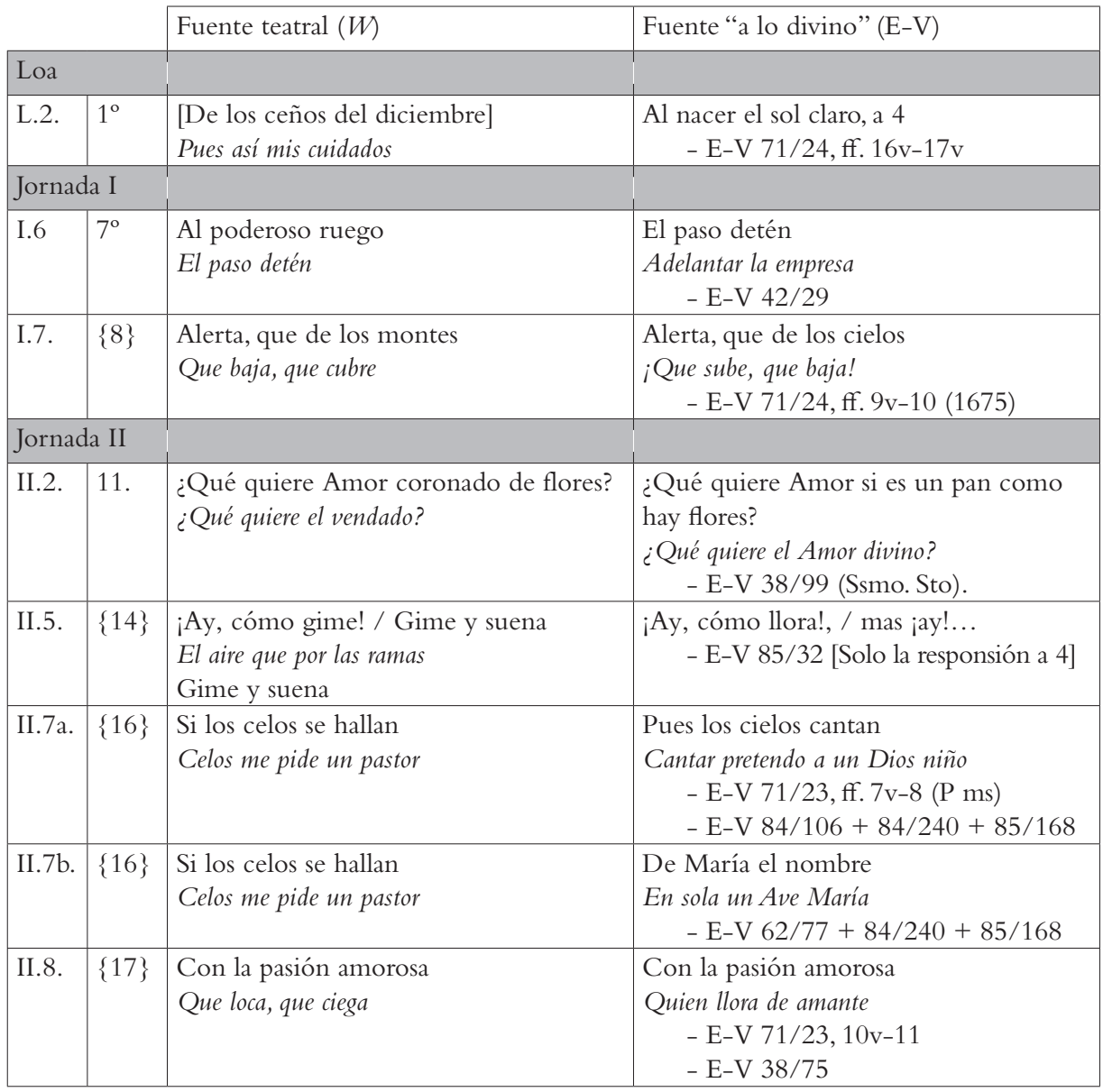

Volviendo a Los celos hacen estrellas, partimos de la base de que, para la elaboración de sus villancicos "sobre la tonada", parece ser que Camargo no tomó en consideración -o incluso es probable que ni siquiera llegara a conocer- 
aquellos tonos de la zarzuela en cuestión que, como ya he dicho, no nos consta que circularan entre los músicos y, de ese modo, llegaran a diversos centros o instituciones fuera de la corte, a saber: los tonos polifónicos a dúo o a cuatro ${ }^{36}$ y las canciones estróficas de una sola sección.

Así pues, solamente las tonadas biseccionales de la zarzuela fueron asimiladas por Gómez Camargo al incorporarlas en determinados villancicos propios, tras un proceso de "divinización" de sus contenidos literarios, como se puede ver en el cuadro 1, pero no nos consta que todas ellas lo fueran. Los casos más claros a este respecto son los tonos L.4 y I.4 del apéndice 1, obras que se conservan en el archivo vallisoletano exclusivamente en su versión profana, pero de las que no se ha localizado hasta la fecha sus correspondientes contrafacta. Tampoco se han localizado "divinizaciones" de los tonos II.1, II.6 y L.3 (aunque en estos dos últimos casos tampoco hay fuentes "humanas" en Valladolid) ${ }^{37}$.

A continuación, pasaré revista a los villancicos "sobre la tonada" que sí se conservan actualmente en $\mathrm{E}-\mathrm{V}$ :

1) L.2. De la loa de la zarzuela he localizado solamente una versión polifónica "a lo divino" del estribillo de L.2., convertido en el estribillo "Al nacer el sol claro" indudablemente compuesto por Miguel Gómez Camargo a partir del estribillo del solo de Juan Hidalgo ${ }^{38}$ (cursivas del autor).

\section{Estribillo}

Pues así mis cuidados del yelo de un desdén están temblando. $(W$, vv. 65-66)
[Estribillo]

Al nacer el sol claro

morir la oscuridad, está temblando.

(E-V 71/24, ff. 16v-17)

Se trata, pues, de una versión a solo de tenor y a cuatro (SSAT) de un villancico al Nacimiento, "sobre la tonada", localizado en el Borrador de los villancicos de Navidad de 1675 (E-V 71/24, ff. 16v-17).

\footnotetext{
${ }^{36} \mathrm{Ni}$ los cuatros asignados a la "Música", a las "Labradoras", a las "Diosas" y a "Todos" (I.1, II.9 a II.11 y II.13) -con la excepción de la canción de Temia II.5, que incluía una sección polifónica- ni tampoco el dúo de Marte y Mercurio (II.12); tampoco se volvieron "a lo divino" las tonadas estróficas, ya fueran en compasete (I.2 y I.3) o en proporcioncilla (II.4).

${ }^{37}$ Quizá el extravío de los Borradores de villancicos de Navidad de 1673 y de Corpus de 1674 puede explicar la pérdida de alguna de las composiciones relacionadas con Los celos hacen estrellas, aunque en el caso de los villancicos sobre la tonada también sería casualidad y mala fortuna que no se hubiera conservado tampoco el juego de partichelas o, aunque fuera, alguna voz suelta en los legajos de obras incompletas (E-V 84, 85 u 86) que atestiguara actualmente su pasada existencia.

${ }^{38}$ En el manuscrito de San Francisco, US-SFs SMMS MS 1/8, f. 8, el tono aparece atribuido a [José] Marín, pero resulta altamente improbable que fuera así. Solo someto a consideración las concordancias musicales, no así las literarias.
} 


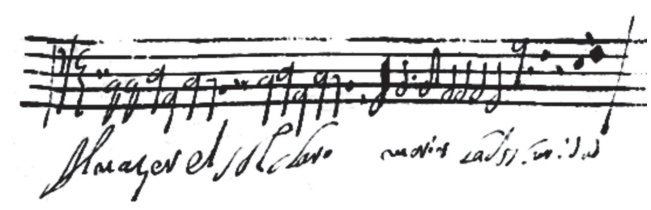

Ilustración 7. E-V 71/24,ff. 16v-17, Al nacer el sol claro, cc. 1-12. Copia de Gómez Camargo

Como puede comprobarse al compararla con la transcripción publicada por Jack Sage ${ }^{39}$, la melodía del estribillo de Camargo -a cargo del tenor- es casi igual a la de Juan Hidalgo. Con toda probabilidad la sección de coplas, que en este caso precedía al estribillo, era a solo de tenor, tal y como aparece copiada la melodía teatral por Miguel Gómez Camargo -en este caso sin el acompañamiento- en el mismo manuscrito, pero unos folios antes (f. 4r), pero el texto "a lo divino" desgraciadamente se ha perdido ${ }^{40}$. Así pues, el villancico resulta incompleto y, dado que tampoco he localizado el correspondiente juego de partichelas, su interpretación hoy por hoy resulta inviable.

En el estribillo "a lo divino" el proceder es el habitual para los contrafacta de este compositor: en primer lugar, expone sin modificación alguna la melodía original en la que se basa -transportada una octava grave, a la tesitura del tenory a continuación elabora una responsión a cuatro voces (SSAT) sobre esa misma tonada en la que predomina la textura homofónica y homorrítmica, alternando a veces con el tenor solista ${ }^{41}$.

2) I.6. Al poderoso ruego / El paso detén

En Los celos hacen estrellas se trata de un tono biseccional (Coplas - Estribillo) entonado fuera de escena por Amor en la primera jornada de la zarzuela, interrumpiendo el diálogo entre Júpiter e $\mathrm{Isis}^{42}$. Amor no participa activamente en dicha escena, pero trata de influir en ella primero persuadiendo a la ninfa mediante el canto de las cinco coplas de la tonada estrófica para que acceda a los requerimientos de Júpiter y luego, en el estribillo,

${ }^{39}$ J. Vélez de Guevara: Los celos hacen..., p. 247.

${ }^{40}$ Tampoco en el legajo de textos de villancicos de la catedral de Valladolid se conserva este poema. Sobre dicho fondo poético véase Carmelo Caballero Fernández-Rufete: "En el principio era el verso': textos de villancicos en la catedral de Valladolid (1640-1725)", Revista de Musicología, 42, 2, 2019, pp. 533-570.

${ }^{41}$ En "Miscent sacra profanis...", C. Caballero Fernández-Rufete se refiere a esta tipología de villancico con la no muy feliz expresión "villancico con doble exposición del estribillo".

${ }^{42}$ En la caja MC/3880 de la Biblioteca Nacional las diferentes partichelas del tono se encuentran (suponemos que por error) en carpetillas distintas: las correspondientes al acompañamiento (con su portadilla en el reverso) y a la parte vocal del estribillo se localizan en E-Mn MC/3880/11, mientras que la parte vocal de las coplas se encuentra en E-Mn MC/3880/6, inserta en la carpeta del villancico de Navidad Ya la real capitana, de Juan Hidalgo. 
advirtiéndole del peligro e inutilidad de su huida ${ }^{43}$. En el archivo de la catedral de Valladolid no hemos localizado copia alguna de esta tonada ni en los Borradores de Miguel Gómez Camargo ni en los legajos de papeles sueltos, aunque sí hemos identificado las melodías de ambas secciones del tono teatral en un villancico al Santísimo Sacramento "sobre la tonada" a 8 voces $(\mathrm{SSAT}, \mathrm{SATB})^{44}$, que no obstante presenta las secciones en posición invertida respecto al modelo teatral, esto es, primero figura el estribillo, "El paso detén", y a continuación siete coplas modeladas sobre la tonada estrófica de las coplas de la zarzuela. Como es habitual en los villancicos de dicho maestro de capilla, las melodías a solo se encomiendan al tenor -en este caso del segundo coro- por lo que aparecen trasportadas a la octava grave respecto al original.

AMOR cantando dentro
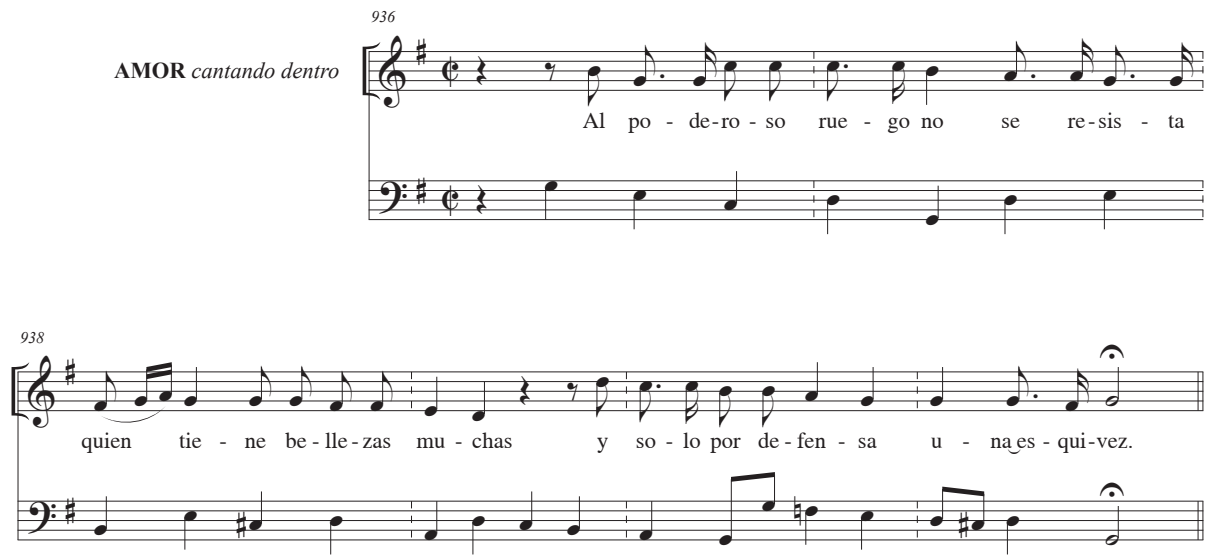

Ejemplo 1. E-Mn MC/3880/11, Juan Hidalgo: "Al poderoso ruego" 45

${ }^{43}$ Este es uno de los pocos casos conservados en fuentes musicales españolas -aparte del MS Contarini de la Biblioteca Marciana- en que una tonada estrófica se anota ad longum, lo cual es muy significativo y resulta muy útil a la hora de conocer los diferentes modos de adaptación de una melodía estrófica a los distintos versos que presentan en estrofas sucesivas variantes en la acentuación, sinalefas u otras diferencias respecto al modelo inicial.

${ }^{44}$ E-V 42/29. Probablemente la razón de la falta de la partitura original del maestro de capilla tanto del tono profano como del borrador autógrafo del villancico sea que en la serie de Borradores de villancicos de Corpus faltan los cuadernos correspondientes a los años 1673-1675, justo aquellos en los que tuvo lugar la producción de villancicos sobre las tonadas de Los celos hacen estrellas.

${ }^{45}$ Jack Sage incluyó la transcripción completa en J. Vélez de Guevara: Los celos hacen..., pp. 254-256. Aunque el original está en chiavette no efectuó transporte alguno de la música. Para facilitar la comparación con la fuente vallisoletana "a lo divino" la transporto una cuarta inferior. 

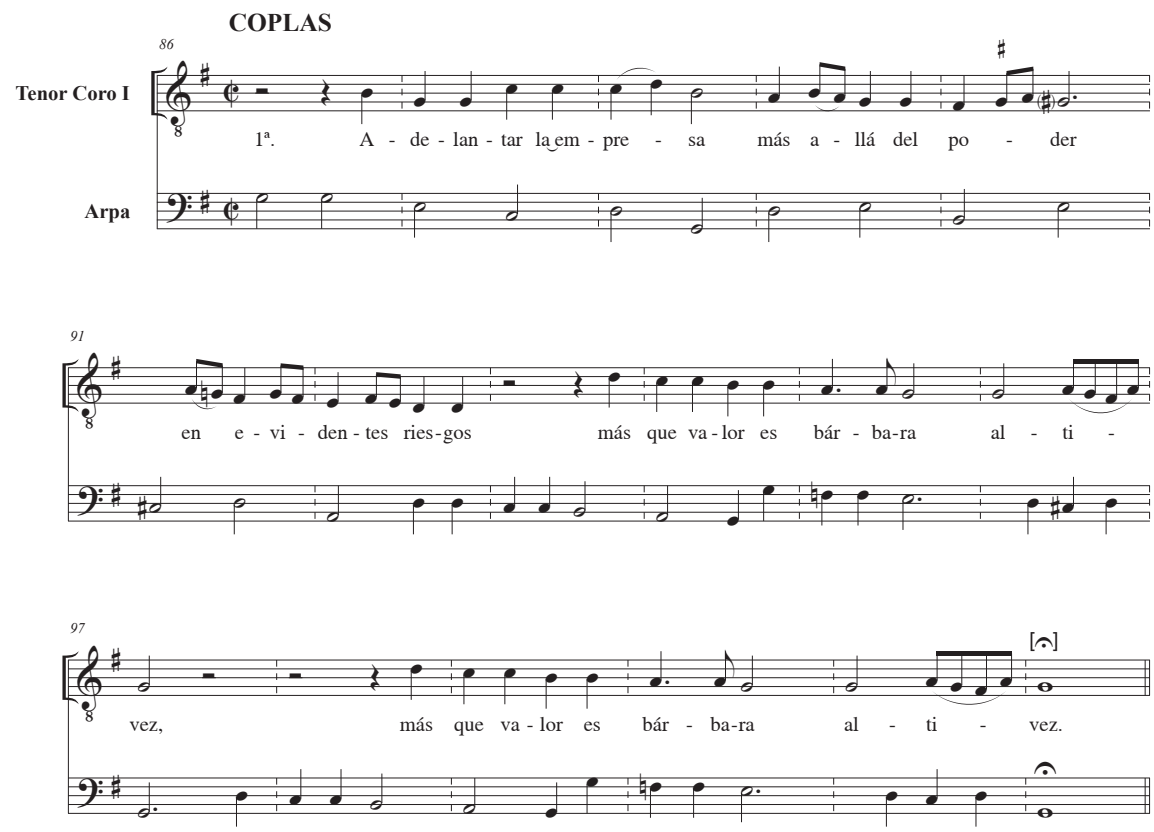

Ejemplo 2. E-V 42/29, Miguel Gómez Camargo: Adelantar la empresa, tenor I

Si comparamos ambas versiones, tal y como puede observarse en los ejemplos precedentes, vemos que Miguel Gómez Camargo (ejemplo 2) anota la copla con las figuras musicales en valores duplicados respecto a la fuente teatral madrileña (ejemplo 1), hecho relativamente frecuente en el repertorio en compasete. Además, dado que en el juego de partichelas del villancico solo figura la melodía de la primera copla es imposible percibir todas las pequeñas variantes y matices rítmico-melódicos introducidos por el copista al anotar las coplas ad longum en la fuente de la Biblioteca Nacional. Las raras variantes -a excepción de la repetición íntegra del último verso en la fuente "a lo divino"son escasamente significativas y no alteran la percepción de que se trata de la misma música, aunque diversamente amplificada y ornamentada.

También afectan a la extensión de la melodía las diferencias que encontramos entre ambas versiones en el estribillo, "El paso detén": frente a la versión madrileña, que tiene una duración de 36 compases de proporción menor ${ }^{46}$, el contrafactum vallisoletano, con sus 23 compases, resulta mucho más concentrado o "económico" en las repeticiones; además, en este caso también se acusan numerosas variantes en la ornamentación, diferente y más profusa en la versión teatral (véase al respecto el apéndice 2). No debemos perder de vista que, en el estribillo de la

\footnotetext{
${ }^{46}$ Ed. de Jack Sage en J. Vélez de Guevara: Los celos hacen..., pp. 255-256.
} 
composición religiosa, al inicial solo de tenor le sigue una responsión policoral basada en dicha tonada a solo; es esta quizá una de las causas que coadyuvan a explicar el por qué Camargo incorpora la melodía inicial del estribillo menos ornamentada y en formato más breve que la que nos propone la fuente madrileña del tono original, puesto que en la responsión las voces de ambos coros van a reiterar una y otra vez los giros melódicos y pequeños melismas propios de la melodía base, saturando el discurso musical de semínimas ornamentales.

3) I.7. ¡Alerta, que de los montes! / El paso detén

Ya he apuntado en páginas precedentes las características y peculiaridades del tono humano de Guerau conservado en E-Mn MC/3880/5. No he encontrado en la literatura secundaria explicación alguna, satisfactoria o no, sobre las discrepancias existentes en el texto poético de ambas fuentes ni tampoco discusión alguna sobre la pertinencia de la atribución de este fragmento a Garau y su más que cuestionable participación en la composición de la música de Los celos hacen estrellas ${ }^{47}$. Una de las escasas alusiones a este tono -relativas al estilo musical de la melodía de Guerau y su semejanza con el estilo de Juan Hidalgo, pero no a su autoría o a la pertinencia de tal atribución- se encuentra en la monografia Songs of Mortals, de Louise K. Stein, en la que comenta:

Más adelante en el Acto I Mercurio canta “iAlerta que de los montes!” fuera de escena para advertir a Júpiter de la llegada de Juno. Esta canción se atribuye a Francisco Guerau, cantante y guitarrista de la Capilla Real, pero estilísticamente es indistinguible de una pieza de Hidalgo. Además, al igual que las canciones de Hidalgo para esta zarzuela, la relación semántica entre texto y música se manifiesta en una figura musical aislada. La versión musical presenta un único recurso para ilustrar su texto metafórico (Juno, "la ira de los cielos, llega envuelta en nieve"), un melisma de seis notas en la palabra "huye" de la frase "cuando diciembre se acerca mayo huye"48 [Véase el ejemplo 3].

ESTRIBILLO

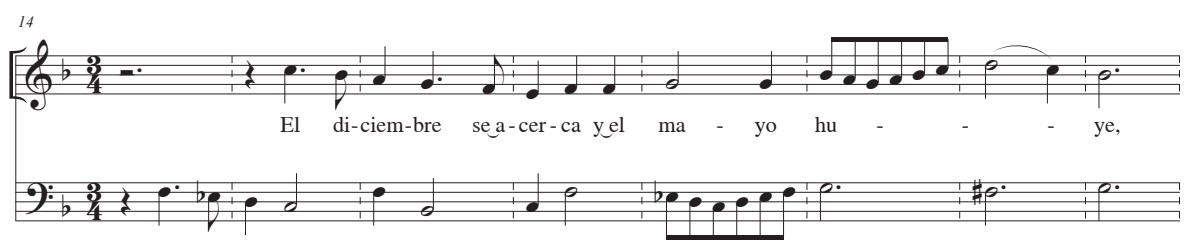

Ejemplo 3. E-Mn MC/3880/5, El diciembre se acerca, cc. 14-21

${ }^{47}$ Antoni Pizà: Francesc Guerau i el seu temps, Palma de Mallorca, Institut d'Estudis Baleàrics, 2000.

${ }^{48}$ L. K. Stein: Songs of Mortals..., pp. 293-294: "Later in Act I, ¡Alerta, que de los montes!' is sung by Mercurio off-stage to warn Júpiter of Juno's arrival. This song is ascribed to Francisco Guerau, a singer and guitarist in the Royal Chapel, but it is stylistically indistinguishable from a Hidalgo piece. Moreover, like the Hidalgo songs for this zarzuela, the semantic relationship between text and music is manifest in one isolated music figure. The musical setting has only one device to illustrate its strikingly metaphorical text (Juno, 'the anger of the skies, arrives enveloped in snow'), a six-note melisma in the word 'huye' (flees) from the phrase 'when December approaches May flees"'. Traducción del autor. 
En el Borrador de los villancicos de Navidad de 1675, ff. 9v-10, encontramos la partitura de un villancico al Nacimiento a 8 voces (SSAT, SATB) y acompañamiento al arpa titulado ;Alerta, que de los cielos ${ }^{49}$, que, a todas luces, es una versión "a lo divino" del tono de Mercurio. Si comparamos este villancico de Gómez Camargo con el tono "humano" de Guerau queda claro que el mallorquín no solo compuso ex novo la música para su nuevo estribillo, El diciembre se acerca, sino que la música para el romance que lo precede también es diferente a la que presenta la fuente vallisoletana "a lo divino" para la misma sección, y que supuestamente es igual o muy similar a la original de Juan Hidalgo (cursivas del autor).

Alerta, que de los montes, por lisonja del otubre baja, desatado en nieve, el enojo de las nubes.

( $W$, vv. 986-989)
Romance Alerta, que de los cielos, a lisonjas de la gracia baja un niño Dios en carnes del desnudo haciendo gala.

(E-V 56/3, vv. 1-4)

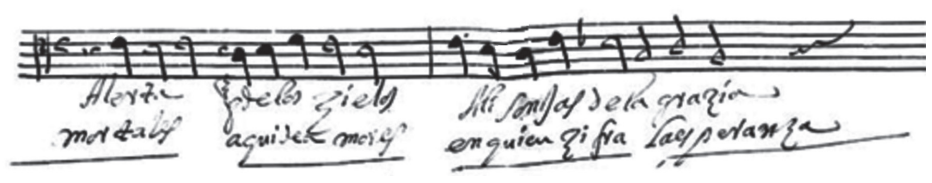

Ilustración 8. E-V 56/3, Alerta que de los cielos, tenor II, fragmento inicial del Romance

El texto de las cinco coplas restantes del villancico navideño nada tiene que ver con las del original teatral, como por otra parte es habitual en las secciones estróficas de los villancicos "sobre la tonada". Lo que sí prescribe el ejemplar en partichelas es una particular división de las coplas: tras la interpretación de un primer grupo de cuatro se canta por primera vez el estribillo -tanto la tonada como la responsión a ocho- para pasar a continuación a cantar las dos últimas coplas y repetir, presumiblemente, la interpretación del estribillo (T II Solo + Responsión a 8). Con respecto a la música, las coplas pares presentan una elaboración polifónica de la melodía previamente expuesta por el tenor II a solo en las impares, alternando así en la primera sección del villancico la monodia acompañada y la polifonía (véase apéndice 3,cc. 16-36). En el ejemplo 4, a continuación, reconstruyo la sección de coplas del tono tal y como debió componerlo Juan Hidalgo, obtenido al aplicar al texto de Juan Vélez de Guevara la melodía que propone Miguel Gómez Camargo en su villancico ;Alerta que de los cielos!

\footnotetext{
${ }^{49}$ El juego de partichelas, localizado en E-V 56/3, atribuye la obra a Miguel Gómez Camargo.
} 

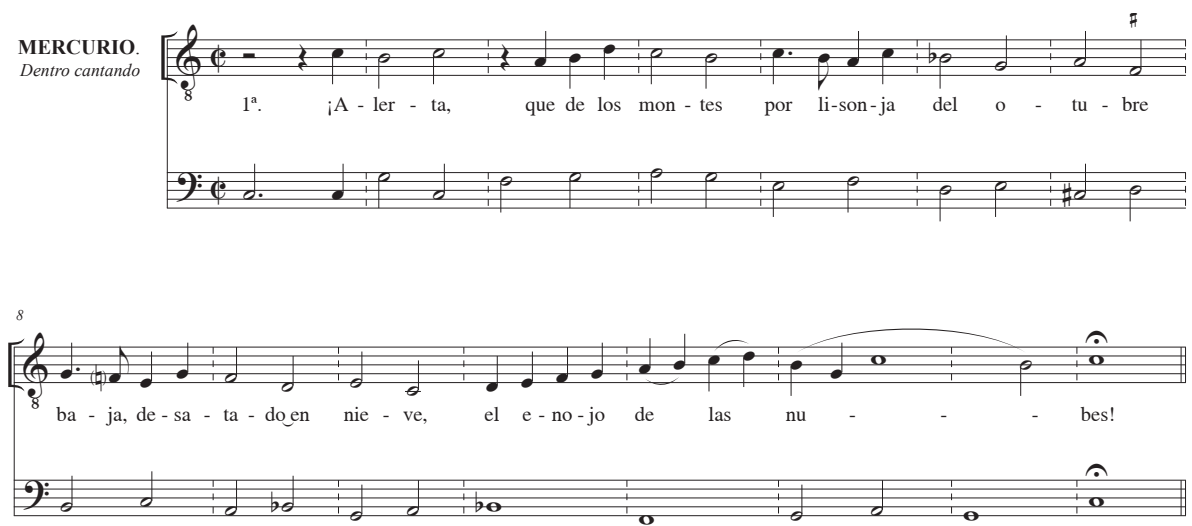

Ejemplo 4. [¿Juan Hidalgo?]: “'Alerta, que de los montes!” Reconstrucción de Carmelo Caballero Fernández-Rufete

Si comparamos la versión obtenida en la reconstrucción con el tono humano de Guerau conservado en la Biblioteca Nacional se observan diferencias apreciables en varios parámetros musicales, desde las distintas tonalidades a la diversa articulación en frases musicales -semiestrofas en Guerau y octosílabos en Gómez Camargo- y a la propia construcción: el mallorquín compone toda la copla básicamente con una única melodía, la cual transporta a la cuarta inferior en la segunda mitad de la estrofa, mientras que Gómez Camargo - ¿o fue Juan Hidalgo?- propone una elaboración secuencial solo en los versos centrales de la cuarteta, enmarcando éstos en dos frases musicales diferentes correspondientes a los versos inicial y final de la copla. Por último, la versión reconstruida resulta mucho más efectiva a la hora de describir musicalmente el texto, para lo cual usa diversos recursos: aísla entre silencios el interjectivo aviso inicial, “iAlerta!”; ilustra los versos centrales “por lisonja del otubre / baja desatado en nieve" mediante el amplio recorrido descendente por grados conjuntos de terceras encadenadas, que contrasta con el súbito ascenso en valores demediados para describir "el enojo de las nubes". Dicho todo lo cual, no me parecen equiparables la versión del tono de Guerau y la compuesta supuestamente por Hidalgo ni en cuanto a la construcción musical ni respecto a los elementos descriptivos y/o retóricos que pone en juego para la ilustración musical del texto ${ }^{50}$.

${ }^{50}$ En este sentido, no creo que sean musicalmente indistinguibles los tonos de Guerau e Hidalgo ni tampoco que la relación semántica entre texto y música se limite a una única figura musical del estribillo de la pieza para ilustrar la palabra "huye", tal y como afirmaba Stein en el párrafo anteriormente citado. Otra cosa muy diferente es que esa melodía, creada expresamente para la primera copla, no resulte tan adecuada para expresar el contenido poético de las cuartetas restantes, cosa harto común en las composiciones estróficas. 
Con respecto al estribillo del villancico -ya que el del tono humano de Guerau nada tiene que ver con la zarzuela- el texto "a lo divino" se configura de modo semejante al que nos propone Juan Vélez en su obra por lo que respecta al número, la métrica y la acentuación de los versos, aunque en este caso no coinciden en la rima:

Que baja, que cubre de rayos las selvas, de asombros las luces. (Los celos hacen estrellas)
Que sube, que baja

la tierra a ser cielo

y el cielo a unas pajas.

(;Alerta, que de los cielos!)

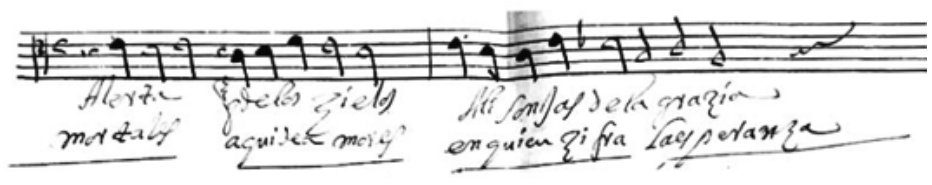

Ilustración 9. E-V 56/3, Alerta que de los cielos, tenor II, fragmento inicial del Estribillo

Por lo que respecta a su música, el villancico está dividido -tal y como sucedía en la previa sección de coplas- en dos subsecciones: una primera a solo de tenor, donde se presenta el estribillo supuestamente original de Hidalgo y una elaboración policoral a ocho voces de los dos motivos melódicos contrastantes presentes en la tonada, que se muestran en la ilustración 9: una célula mínima de tres notas, repetida a la cuarta inferior-que recuerda vagamente al motto del estribillo ¡Que loca, que ciega!, del tono "Con la pasión amorosa", del segundo acto de la zarzuela- para el primer verso y un motivo escalístico de más amplio aliento para los dos últimos, "la tierra a ser cielo / y el cielo a una pajas", emparentado en cierto modo con "el enojo de las nubes" de la sección anterior; este se presenta tanto en dirección ascendente como descendente con el fin de ilustrar las subidas y bajadas que propone el texto del villancico. La impresión general es que el breve texto del estribillo, amplificado mediante su repetición, se articula en un único arco ascendente-descendente notablemente equilibrado. Si asumimos la versión vallisoletana como un contrafactum de la versión original escénica, la conclusión que podemos extraer es que Guerau, al elaborar su tono humano (no necesariamente destinado al teatro), utilizó exclusivamente el texto literario del romance y le añadió un estribillo completamente nuevo y ajeno a la zarzuela. Respecto a la música, ambas secciones eran de nueva creación, probablemente obra del mallorquín, y nada tiene que ver con la música original de la zarzuela. 
4) II.2. ¿Qué quiere Amor coronado de flores?

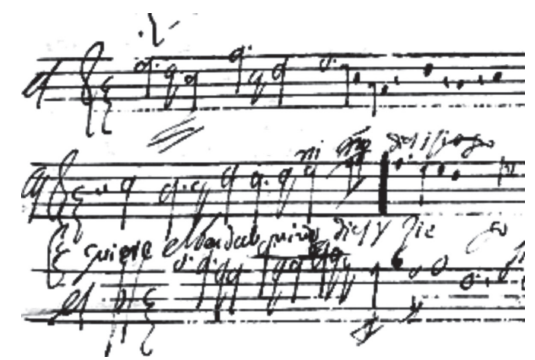

Ilustración 10. E-V 84/257. ¿Qué quiere Amor?

Comienzos del Estribillo y de las Coplas. Copia de Gómez Camargo

La versión "a lo divino" que se ha conservado en el archivo de la catedral deValladolid de este tono es un contrafactum al Santísimo Sacramento copiado por fray Lucas Bueno. La música del villancico, que se conserva como anónima en EV 84/257, pero que podemos atribuir sin duda a Gómez Camargo, es a 8 voces (SSAT, SATB) y acompañamiento al arpa, y el juego de partichelas se localiza en E-V 38/99. Se trata nuevamente de un villancico "sobre la tonada" de los más comunes, puesto que no encontramos en el mismo variantes reseñables ni en su sección inicial (esto es, en la tonada original con el texto "a lo divino") ni en las coplas: no encontramos adición de instrumentos, variantes ornamentales ni amplificación alguna, salvo la circunscrita a la responsión policoral del estribillo, donde el compositor estableció su habitual juego de coreados, con pasajes predominantemente homorrítmicos puntuados por breves secciones polifónicas.

5) II.5. ¡Ay cómo gime!

En el reverso de una de las copias conservadas en Valladolid de la canción de Temia y la correspondiente responsión de las ninfas en la escena de la lapidación de Momo (E-V 85/32) se encuentra un fragmento a 4 voces (SSAT) autógrafo de Miguel Gómez Camargo. Aunque carece prácticamente de todo el texto parece una versión de la responsión a cuatro del tono de la zarzuela algo distinta a la que aparece en el anverso del papel. Los únicos fragmentos de texto que aparecen en ella son el comienzo "¡Ay, que las..." y, más adelante, "llora, mas jay!” y "de incendios". La relación con el cuatro de la zarzuela se deduce del análisis de la música, que parece estar completa y que utiliza giros melódico-rítmicos tomados del original teatral. Todo parece indicar que se trataba de un cuatro al Nacimiento, pero no podemos afirmarlo con rotundidad, pues con los escasos datos que nos proporciona la fuente la búsqueda de concordancias lamentablemente ha resultado infructuosa.

6) II.7. Si los celos se hallan 
Quizá el tono de la zarzuela más difundido en su época y en los años inmediatamente posteriores $^{51}$, no se conserva ni en la caja $\mathrm{MC} / 3880$ de la Biblioteca Nacional ni en el archivo catedralicio vallisoletano. Sin embargo, de su innegable recepción en la seo pinciana queda constancia por la presencia de dos villancicos "sobre la tonada" elaborados sobre esta canción, uno de Navidad, Pues los cielos cantan (E-V 85/168) ${ }^{52}$, y el otro a diversas fiestas de la Virgen, De María el nombre (E-V 62/71). El estribillo del villancico navideño respeta la métrica, la rima y presenta cierto parecido con los versos primero y último del romancillo; por el contrario, el contrafactum mariano es casi totalmente ajeno al tono teatral desde el punto de vista textual, respetando solo -como no podía ser de otro modo-la métrica del modelo:

$\begin{array}{lll}\begin{array}{l}\text { Si los celos se hallan } \\ \text { donde amor se pierde, }\end{array} & \begin{array}{l}\text { Pues los cielos cantan } \\ \text { ¿de qué amor se duele? }\end{array} & \begin{array}{l}\text { De María el nombre } \\ \text { que del cielo baja }\end{array} \\ \begin{array}{c}\text { ¿para qué los busca } \\ \text { quien ya los tiene? }\end{array} & \begin{array}{c}\text { El llorar finezas } \\ \text { por bien se tiene. }\end{array} & \begin{array}{l}\text { todas las dulzuras } \\ \text { de amor ensalza. }\end{array} \\ & (\text { E-V } \text {-V } 104 / 168, \text { vv. } 1-4) & (\text { E-V 62/71, vv. 1-4) }\end{array}$

Más interesante resulta la música, que es exactamente igual para los dos villancicos (o sea, el segundo es una mera retextualización del primero); aunque lo hemos considerado un villancico "sobre la tonada" lo cierto es que no se ajusta por completo a tal tipología debido a que la primera exposición del estribillo (que generalmente respeta el modelo profano punto por punto) en este caso se presenta "coloreada" por tres partes instrumentales (ssb) que intervienen a lo largo del mismo.

Mediante este procedimiento Miguel Gómez Camargo aporta elementos de su propia cosecha a la exposición de la tonada en diferentes parámetros musicales al dar concreción a la armonía, ornamentar la melodía y enriquecer la tímbrica. A esta primera sección le sucede la habitual responsión policoral, con el típico contrapunto coral homofónico y homorrítmico, esta vez enfatizado por el contraste entre un coro primero puramente vocal y el segundo, predominantemente instrumental.

${ }^{51}$ Se conservan copias del tono teatral en E-Mn 13622, f. 27, E-SCu Ms 265. ff. 31v-32 y I-Vnm MS Italiani, pp. 82-86. De esta última fuente tenemos la transcripción de Jack Sage en J. Vélez de Guevara: Los celos hacen..., pp. 265-266.

${ }^{52}$ Hay grabación en CD: Tíreme flechas Amor. Música barroca de la catedral de Valladolid [CD de audio], Alexandrina Polo Elorri, María del Mar F. Doval e. a., Gerardo Arriaga (dir.), s. 1., Las Edades del Hombre / Ópera tres, 1999. CD 1030-ope. 

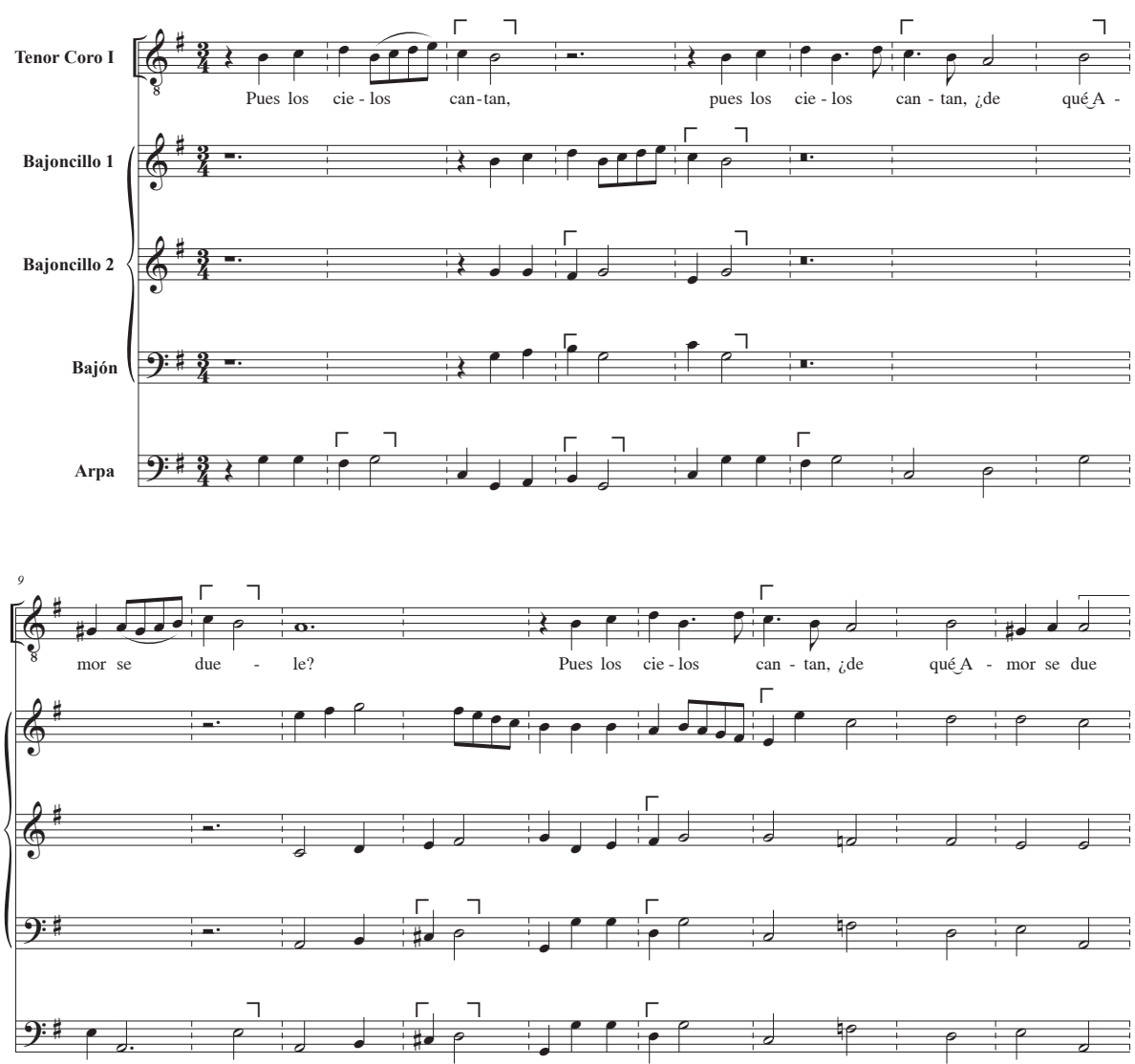

Ejemplo 5. E-V 62/77 + 84/240 + 85/168. [M. Gómez Camargo]: Pues los cielos cantan, cc. 1-19

La sección de coplas del villancico -ya sea del navideño o del mariano, pues ya he apuntado que son musicalmente idénticos- sorprendentemente no se elabora sobre las coplas del tono original de la zarzuela, "Celos me pide un pastor". Sin embargo, parece ser que la melodía tampoco fue compuesta por el maestro de capilla deValladolid. En realidad se trata de un nuevo contrafactum de una obra diferente de Juan Hidalgo, perteneciente a la anónima zarzuela Contra el amor desengaño, ocasionalmente atribuida a Calderón. Aunque no se ha conservado fuente musical alguna del tono "Cantar pretendo, Florilla" sí está atestiguada su transmisión como "tono" en diversos manuscritos poéticos ${ }^{53}$. El texto de la primera copla en ambas fuentes dice así:

\footnotetext{
${ }^{53}$ Por ejemplo, en E-Bc MS 888, f. 39 y en E-Bc MS 1596, [63].
} 


\author{
Cantar pretendo, Florilla, \\ en tu hermosura y tu gracia, \\ pues tu perfección al canto \\ afina las consonancias. \\ Por aquí sí que suena, \\ deleita y agrada \\ la voz que se alienta \\ con tal alabanza.
}

\section{(Contra el Amor desengaño, I)}

\author{
Cantar pretendo a un Dios niño \\ que con belleza y con gracia \\ llorando a un rigor del canto \\ afina las consonancias. \\ que al compás de sus perlas \\ los puntos se hallan \\ de amor más ardientes, \\ más claros que el agua.
}

(E-V 85/168, vv. 5-15)

La partitura de las coplas, copiada por Miguel Gómez Camargo, se encuentra en el Borrador de los villancicos de Navidad de 1674, inmediatamente a continuación del estribillo Pues los cielos cantan. El problema surge al cotejar la bibliografía secundaria, pues se ha propuesto como posible fecha de estreno de la zarzuela atribuida a Calderón de la Barca tanto 1684 como $1679^{54}$, o sea, cinco o nueve años después de la copia del citado borrador de villancicos. Así pues, ¿debemos asumir que la fecha propuesta por la crítica literaria para el estreno de Contra el amor desengaño es errónea? ¿Podemos imaginar que Juan Hidalgo en tal ocasión aprovechó un tono (texto y música) preexistente para trasvasarlo e incorporarlo a dicha zarzuela? Con los datos con que contamos a día de hoy es imposible dar una respuesta totalmente satisfactoria.

Desde el punto de vista musical, lo que nos propone Gómez Camargo en las coplas de los dos villancicos sobre esta tonada es parcialmente reflejo de lo que acontecía en la primera sección del estribillo; esto es, aunque la cuarteta octosilábica de la copla se canta a solo de tenor y acompañamiento, en los cuatro versos subsiguientes presenta la melodía vocal inserta en un entramado polifónico mixto formado por la copia de bajoncillos y el bajón más el tenor solista, tal y como se presentaba en el estribillo inicial.

7) II.8. Con la pasión amorosa

El último villancico del archivo de la catedral de Valladolid relacionado con Los celos hacen estrellas es E-V 38/75, Con la pasión amorosa, al Nacimiento, a ocho voces (SSAT, SATB) y acompañamiento, compuesto para los maitines de Navidad de 1674, sobre la tonada homónima ${ }^{55}$. En la

${ }^{54}$ Kurt Reichenberger, Roswitha Reichenberger: Bibliographisches Handbuch der Calderón-Forschung, Kassel, Thiele \& Schwarz, 1979, p. 755.

${ }^{55}$ La fuente teatral vallisoletana (E-V 71/23, ff. 10v-11) aparece descrita en C. Caballero: "Nuevas fuentes musicales...", pp. 126-127, y editada en ese mismo trabajo y posteriormente en C. Caballero Fernández-Rufete (ed.): "Arded, corazón, arded". Tonos humanos del Barroco en la Península Ibérica, Las Edades del Hombre / Sociedad "V Centenario del Tratado de Tordesillas", 1997, pp. 35, 119-130. A diferencia de lo allí dicho, ya no puede sorprender que Miguel Gómez Camargo copiara la tonada en clave de tenor, pues a día de hoy sabemos que destinar la melodía original a un tenor era la práctica más habitual a la hora de elaborar un villancico "sobre la tonada", como es el caso. 
zarzuela tal tono lo canta Minerva en la segunda jornada de la zarzuela. El villancico modelado sobre dicho tono teatral presenta dos secciones, romance y estribillo, en ese orden. He aquí el texto de la primera copla del romance y del estribillo enfrentado a las mismas secciones del contrafactum:

Con la pasión amorosa ¡qué sin esperanza luchas si el no tener resistencia sus victorias asegura! Que loca, que ciega, que sorda, que muda ni advierte ni mira ni habla ni escucha. ( $W$, II, vv. 1143-1146, 1150-1153)
Con la pasión amorosa de un Dios que con penas lucha a su mayor resistencia más victorias asegura. Quien llora de amante, quien llama y escucha de fino da tierno palabra que busca.

(E-V 38/75, vv. 1-4, 17-20)

El villancico de Miguel Gómez Camargo presenta una secuencia de secciones similar a la que hemos visto anteriormente en ;Alerta, que de los cielos!; esto es, las coplas impares se cantan a solo, como en el teatro, pero las pares presentan una textura polifónica creada supuestamente por Miguel Gómez Camargo para variar la sin duda reiterativa propuesta del romance; en las coplas polifónicas la melodía principal migra desde el tiple segundo al primero y después al contralto, para volver finalmente al tiple primero. Así la melodía original, enmascarada en una sencilla textura homofónica, como puede verse en el ejemplo 6 , resulta perfectamente audible y reconocible.

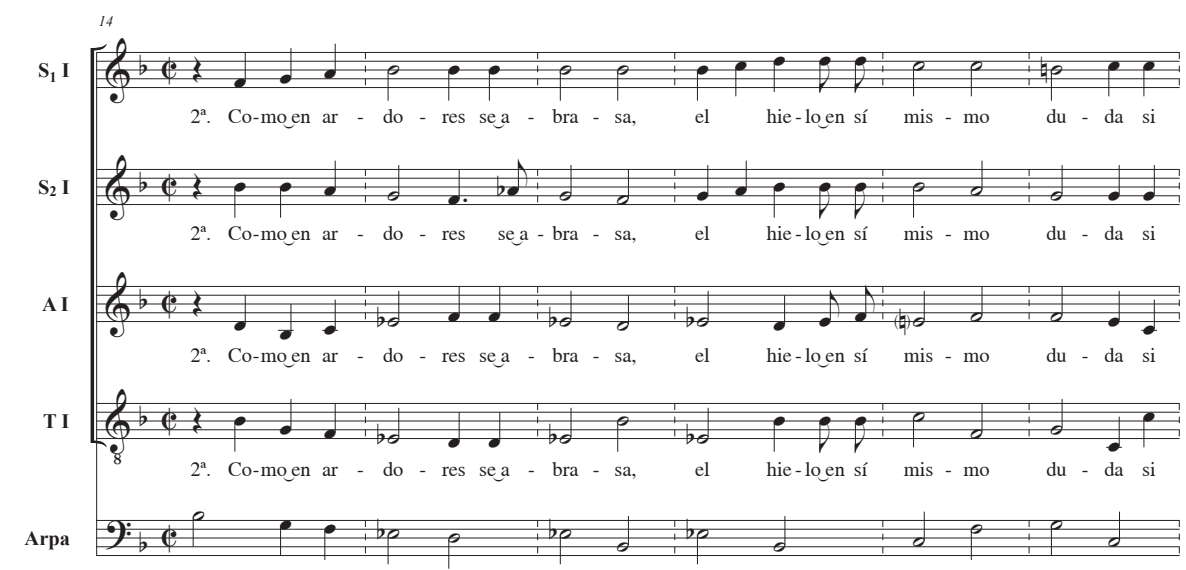




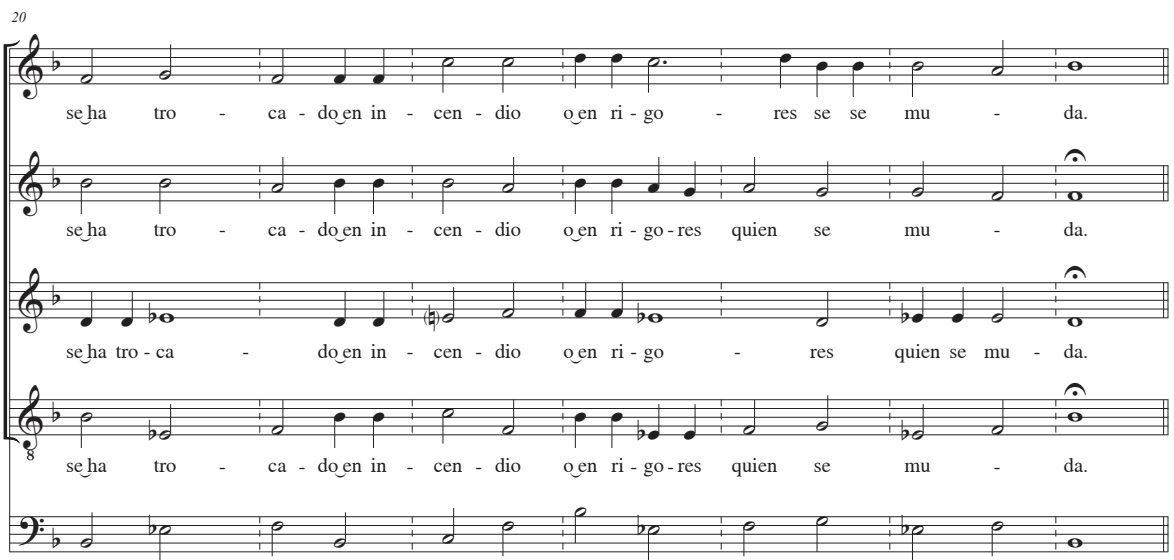

Ejemplo 6. E-V 38/75, M. Gómez Camargo: Con la pasión amorosa, cc. 14-26

\section{Conclusiones}

Es muy probable que todas las fuentes musicales de Los celos hacen estrellas que se conservan actualmente en la caja MC/3880 de la Biblioteca Nacional de Madrid fueran copiadas como un único conjunto homogéneo de fuentes destinadas a la interpretación, elaborado principalmente por un solo copista, y que este bloque fuera, al menos en principio, independiente del resto de los tonos que incluye tal legajo. Probablemente tal grupo de tonos formó el núcleo original, primigenio, de una colección que fue incrementándose paulatinamente a raíz de la adición de numerosos tonos "a lo divino" y "a lo humano" de compositores principalmente contemporáneos de Hidalgo, pero también de otros algo posteriores, todo lo cual cristalizó en la formación del legajo denominado Tonadillas de Hidalgo. El hecho de que la música original de Los celos hacen estrellas se conservara en formato de partichelas sueltas no encuadernadas -que probablemente serían las utilizadas para el estreno de la zarzuela en el Salón Dorado del Alcázar el 22 de diciembre de 1672, como parece sugerir L. Stein ${ }^{56}$ - y no en un solo manuscrito compacto debió propiciar su desmembramiento y eventual pérdida de los fragmentos actualmente desaparecidos o extraviados ${ }^{57}$.

${ }^{56}$ L. K. Stein: Songs of Mortals..., p. 289. La práctica identidad de algunas de estas copias con las fuentes vallisoletanas fechadas en 1674-1675 lo hace francamente viable, mientras que ciertas piezas en manuscritos algo posteriores, como el Libro de tonos de José Miguel Guerra, presentan acusadas diferencias con las fuentes madrileñas, lo que podría indicar un origen diferente y/o más tardío para la fuente compostelana.

${ }^{57}$ Por el contrario, el hecho de que otras fuentes teatrales anteriores como la Fábula de Andrómeda y Perseo (US-Hu Typ.258H) o la ópera Celos aun del aire matan (P-Ep Ms. CL 1/2-1) -además de otras muchas de finales del siglo XVII- se conservaran encuadernadas contribuyó, sin duda, a su conservación. 
Las fuentes de la zarzuela conservadas en Valladolid llegaron a manos de Miguel Gómez Camargo muy pronto, casi inmediatamente después del estreno de la misma, a juzgar por las fechas de los manuscritos en donde se conservan ya sean las fuentes teatrales o ya las partituras de los contrafacta elaborados sobre tales melodías. Sin embargo, las fuentes pincianas denotan una finalidad diferente a la que presentan los manuscritos del legajo madrileño; las copias vallisoletanas -habitualmente anotadas en formato de partitura, sin referencia alguna a su origen teatral ni al autor de los tonos y carentes de los textos literarios originales, al menos parcialmente- no parecen haber estado en momento alguno destinadas a su interpretación -ya que son de todo punto impracticables como fuentes performativas- sino que son ejemplares más propios de un coleccionista. El motivo de su compilación por parte de Miguel Gómez Camargo probablemente fue el conocimiento y estudio de importantes obras de señalados compositores contemporáneos como paso previo para crear, a partir de ellas, composiciones aptas para su interpretación en el ámbito religioso en el que se desenvolvió su actividad musical a lo largo de toda su vida. Toda vez que los textos teatrales eran vueltos "a lo divino" (posiblemente por "su" poeta y contrafactista por antonomasia, fray Lucas Bueno) y que el maestro de capilla componía, como mínimo, una responsión -generalmente policoral- del estribillo los copistas al servicio de la catedral, muy a menudo en colaboración con el propio maestro de capilla, realizaban el consiguiente juego de partichelas que habría de ser utilizado por los miembros de la capilla de música ya en los maitines de Navidad o Reyes o ya en otras festividades (Corpus Christi, fiestas marianas) susceptibles de ser solemnizadas mediante el canto de villancicos. Los originales teatrales o bien eran devueltos a quien se los proporcionó o bien permanecieron en manos del maestro hasta que pasaron al archivo de la catedral en virtud de su legado testamentario.

Siendo este el propósito, parece ser que Miguel Gómez Camargo se interesó poco o nada por aquellas formas estróficas con una única sección musical -como los diversos romances polifónicos o las series de coplas- quizá por considerarlos no susceptibles de ulteriores desarrollos. En cualquier caso, fueran o no enviadas a Valladolid desde la corte, es muy probable que las fuentes de dichos tonos se hayan perdido, y tampoco he logrado localizar ninguna versión de ellas vuelta a lo "divino". Por tanto, todo el interés del maestro de capilla por el repertorio teatral se concentró en las frecuentísimas formas biseccionales "estribillo y coplas" o "romance con estribillo". Así pues, una parte importante de la producción villancística de Miguel Gómez Camargo lo es, en realidad, en implícita y silente colaboración con otros compositores (Juan Hidalgo, Cristóbal Galán, José Marín, etc.) sin que quepa hablar propiamente, a mi entender, de "plagio" en el sentido peyorativo que tiene actualmente este término, pues la técnica de la contrafactura seguía plenamente vigente y fue comúnmente aceptada desde la época medieval hasta el barroco. Así, los productos musicales 
creados por dichos compositores señeros y algunos otros más -estrechamente asociados en su época con las ideas de calidad, refinamiento, y autoridad ${ }^{58}$ - resultaron particularmente atractivos y aptos para su copia, reelaboración y asimilación por parte de Gómez Camargo y otros maestros.

Por lo que respecta al tema de la investigación en torno a las fuentes musicales del teatro aurisecular, la existencia de esta tipología de villancicos "sobre la tonada" nos permite no solo aquilatar determinados procesos que afectaban al repertorio profano y teatral, como la circulación de composiciones procedentes de contextos sociales y festivos ajenos al ámbito religioso, sino valorar los diversos modos y técnicas de manipulación de esas composiciones que empleaban los compositores contemporáneos -en nuestro caso Miguel Gómez Camargo- a la hora de adecuarlas e incorporarlas a los repertorios religiosos en lengua romance. Mediante el estudio de tales villancicos podemos adquirir un conocimiento más ajustado sobre cómo ornamentar y amplificar una melodía, como colorearla tímbricamente, cómo desarrollarla armónicamente y como aplicarle determinados procedimientos retóricos.Y lo que es más importante, nos permite recuperar determinadas melodías perdidas y devolverlas a su estado "humano" original a partir de las divinizaciones localizadas, como hemos visto en el caso del tono "¡Alerta, que de los montes!”.

${ }^{58}$ Es decir, acreedores de un notable capital cultural, según la idea de Pierre Bourdieu, apud K. Ellis: "The Sociology of Music", An Introduction to Music Studies, J. P. E. Harper-Scott, Jim Samson (eds.), Cambridge, Cambridge University Press, 2009, pp. 52-55. 


\section{Apéndices}

Apéndice 1. Fuentes musicales de la zarzuela Los celos hacen estrellas, de Juan Vélez de Guevara y Juan Hidalgo ${ }^{59}$

\begin{tabular}{|c|c|c|c|}
\hline & & Incipit literarios & Fuentes musicales \\
\hline \multicolumn{4}{|c|}{ Los celos hacen estrellas - Loa } \\
\hline L.1. & $(\alpha)$ & A los floridos años & E-Mn MC/3880/24 \\
\hline L.2. & 1 & $\begin{array}{l}\text { De los ceños del diciembre } \\
\text { - Pues así mis cuidados }\end{array}$ & \begin{tabular}{|l} 
E-Mn MC/3880/34 \\
- E-V 71/24, f. 4r \\
- E-SCu MS 265, ff. 16v-17 \\
- US-SFs SMMS MS 1/8, f. 8
\end{tabular} \\
\hline L.3. & 25 & $\begin{array}{c}\text { Peinándose estaba un olmo } \\
\text { - Y viéndole alegre }\end{array}$ & E-Mn MC/3880/20 \\
\hline L.4. & {$\left[\dot{c}^{2} ?\right]$} & $\begin{array}{c}\text { ¿Cómo ha de saber Belilla? } \\
\text { - Porque abrasa más }\end{array}$ & $\begin{array}{l}\text { E-Mn MC/3880/42 } \\
\quad \text { - E-V 84/239 (Prácticamente idénticas) }\end{array}$ \\
\hline L.5. & $(\alpha)$ & $\begin{array}{l}\text { A los floridos años } \\
\text { - Pues así mis cuidados } \\
\text { - Que viéndole alegre } \\
\text { - Porque abrasa más } \\
\text { A los floridos años }\end{array}$ & $\begin{array}{l}\text { E-Mn MC/3880/24 } \\
\text { Vid. supra L.2. } \\
\text { Vid. supra L.3. } \\
\text { Vid. supra L. } 4 . \\
\text { E-Mn MC/3880/24 }\end{array}$ \\
\hline \multicolumn{4}{|c|}{ Los celos hacen estrellas - Primera jornada } \\
\hline I.1. & 3 & Celebren por las selvas & E-Mn MC/3880/38 \\
\hline I.2. & 4 & ¿Quién a las puertas de Marte? & E-Mn MC/3880/9 \\
\hline I.3. & 5 & Juno, que del dios supremo & E-Mn MC/3880/10 \\
\hline I. 4. & $<6>$ & $\begin{array}{l}\text { Recelos, cuidados } \\
\text { - Cuidado que en el poder }\end{array}$ & $\begin{array}{l}\text { - E-V 85/32 } \\
\text { - E-V 84/257 (después del 6/II/1675) } \\
\text { - E-SCu MS 265, ff. 17v-18 }\end{array}$ \\
\hline I.5. & {$[3]$} & Celebren por las selvas & E-Mn MC/3880/38 [Vide supra 1.1.] \\
\hline I.6. & 7 & \begin{tabular}{|l|} 
Al poderoso ruego \\
- El paso detén
\end{tabular} & E-Mn MC/3880/11 y MC/3880/6 \\
\hline I.7. & $\{8\}$ & $\begin{array}{l}\text { Alerta, que de los montes } \\
\text { - Que baja, que cubre }\end{array}$ & E-Mn MC/3880/5 \\
\hline I. 8. & $<9>$ & No, no se asegure & \\
\hline \multicolumn{4}{|c|}{ Los celos hacen estrellas - Segunda Jornada } \\
\hline II.1. & 10 & $\begin{array}{r}\text { De las luces que en el mar } \\
\text { - ¡Ay, qué desdicha! }\end{array}$ & $\begin{array}{l}\text { E-Mn MC/3880/8 } \\
- \text { E-SCu MS } 265 \text {, ff. 9v-10 }\end{array}$ \\
\hline II. 2. & 11 & $\begin{array}{c}\text { ¿Qué quiere Amor coronado de flores? } \\
- \text { ¿Qué quiere el vendado? }\end{array}$ & $\begin{array}{l}\text { E-Mn MC/3880/12 } \\
\quad \text { - E-V 84/257 } \\
\text { - E-SCu MS } 265,10 v-11\end{array}$ \\
\hline II.3. & 12 & La noche tenebrosa & \begin{tabular}{|l} 
E-Mn MC/3880/13 \\
- E-SCu Ms 265. ff. 78-79
\end{tabular} \\
\hline II. 4. & 13 & Sepan todos que a Juno & E-Mn MC/3880/14 \\
\hline
\end{tabular}

${ }^{59}$ Véase la nota 16 donde se describe el significado de los diferentes estilos de texto, tipos de corchetes y sangrados utilizados. Las fuentes musicales se abrevian siguiendo la normativa del RISM. 


\begin{tabular}{|c|c|c|c|}
\hline & & Incipit literarios & Fuentes musicales \\
\hline II.5. & $<14>$ & $\begin{array}{l}\text { ¡Ay, cómo gime! } \\
\text { - Gime y suena } \\
\text { - El aire que por las ramas }\end{array}$ & $\begin{array}{l}\text { - E-V } 85 / 32 \\
\text { - E-V } 71 / 23, \text { ff. } 4 \mathrm{v}-5^{*} \\
\text { * Solo la responsión a } 4\end{array}$ \\
\hline II.6. & $<15>$ & $\begin{array}{l}\text { Al aire se entregue } \\
\quad \text { - En este nuevo alentar }\end{array}$ & $\begin{array}{l}\text { - E-SCu Ms 265, ff. } 21 v-22 r \\
\text { - E-Bc M 3660, ff. 22v-24r }\end{array}$ \\
\hline II.7. & $<16>$ & $\begin{array}{l}\text { Si los celos se hallan } \\
\quad \text { - Celos me pide un pastor }\end{array}$ & $\begin{array}{l}\text { E-Mn Mss/13622, f. } 27 \\
\text { - E-SCu Ms } 265 \text {. ff. 31v-32 } \\
\text { - I-Vnm MS Italiani, 4/470, pp. 82-6 }\end{array}$ \\
\hline II.8. & $<17>$ & $\begin{array}{l}\text { Con la pasión amorosa } \\
\text { - Que loca, que ciega }\end{array}$ & $\begin{array}{l}\text { - E-V 71/23, ff. 10v-11r } \\
\text { - E-SCu Ms 265, ff. 38v-39 }\end{array}$ \\
\hline II.9. & {$[18]$} & Ha de las montañas de Argos & \\
\hline II.10a. & 19 & Aves, fieras, fuentes y ríos & E-Mn MC/3880/15 \\
\hline II.10b. & 20 & Estrellas, luces, planetas $y$ signos & E-Mn MC/3880/16 \\
\hline II.11. & {$[21]$} & [Dioses, ya vienen las selvas] & $\begin{array}{l}\text { (Falta la música de los octosílabos) } \\
\text { Quizá cantado con la música de "Porque, a } \\
\text { pesar del recelo" }\end{array}$ \\
\hline II.12. & 22 & Venid, venid a este sitio & E-Mn MC/3880/17 \\
\hline II.13. & 23 & Porque, a pesar del recelo & E-Mn MC/3880/18 \\
\hline F.1. & 24 & Trompicábalas Amor & E-Mn MC/3880/19 \\
\hline
\end{tabular}


Apéndice 2.Transcripción de las secciones a solo del villancico El paso detén, atribuidas a Juan Hidalgo, E-V 42/17

\section{El paso detén \\ [Tono] al Santísimo Sacramento}

Anónimo [Juan Hidalgo]

Copia de Miguel Gómez Camargo

Signatura: E-V 42/17

Transcripción: Carmelo Caballero Fernández-Rufete

TONADA
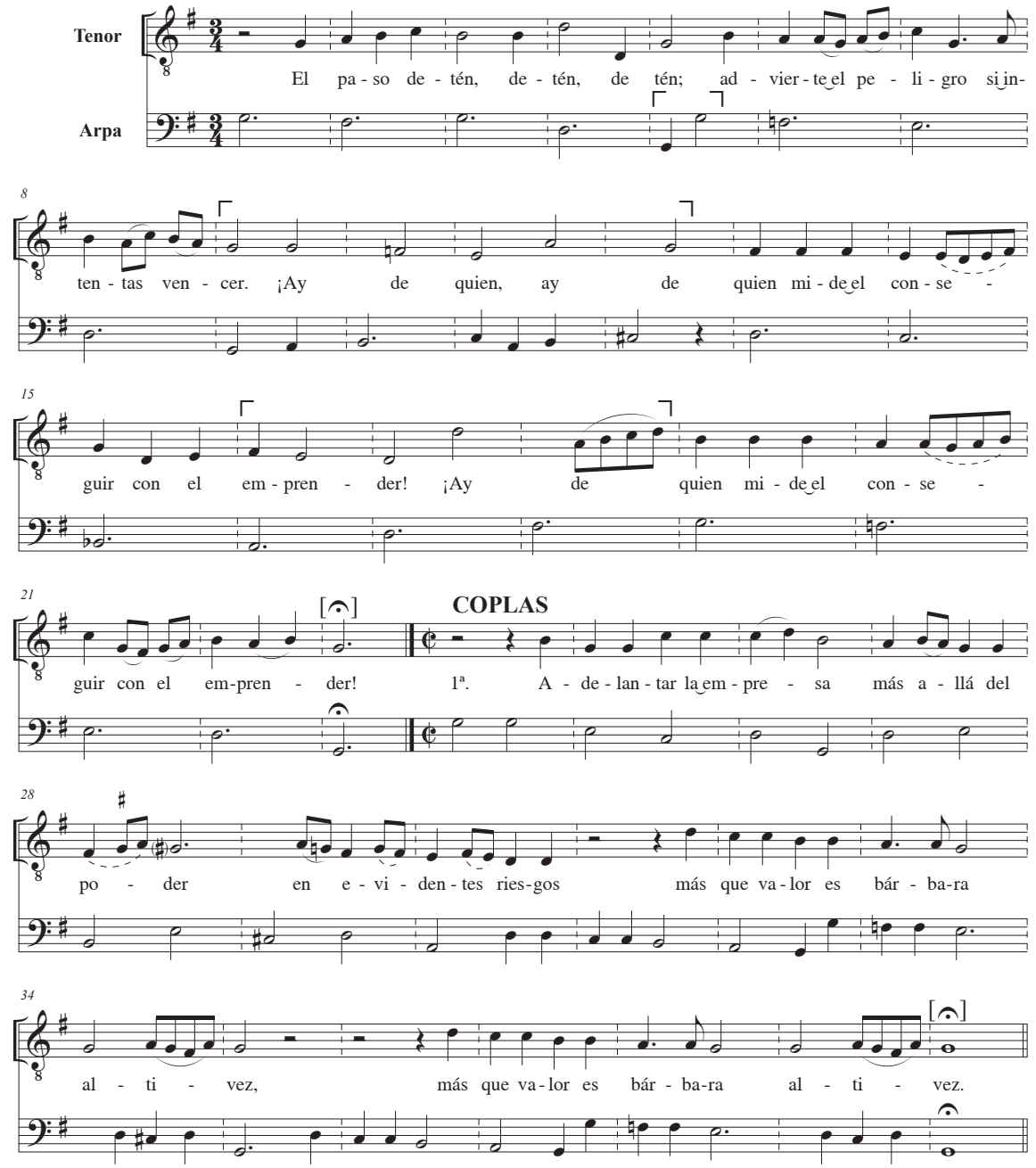
Apéndice 3.Transcripción de Miguel Gómez Camargo: ¡Alerta, que de los cielos!, villancico al Nacimiento, E-V $56 / 3$

\section{¡Alerta, que de los cielos!}

Villancico de Navidad, al Nacimiento

Miguel Gómez Camargo

Signatura: E-V 56/3 Transcripción: Carmelo Caballero Fernández-Rufete
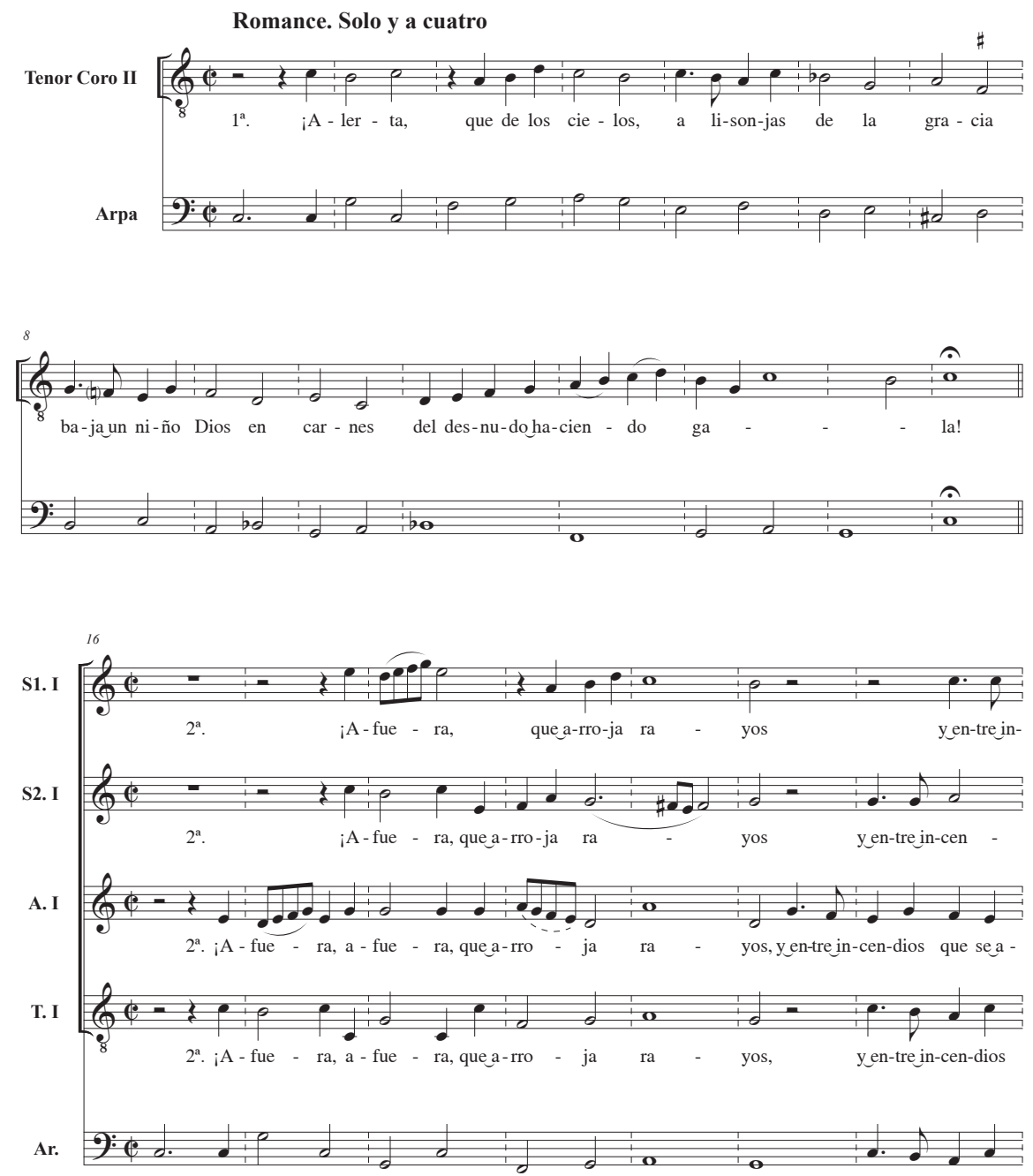

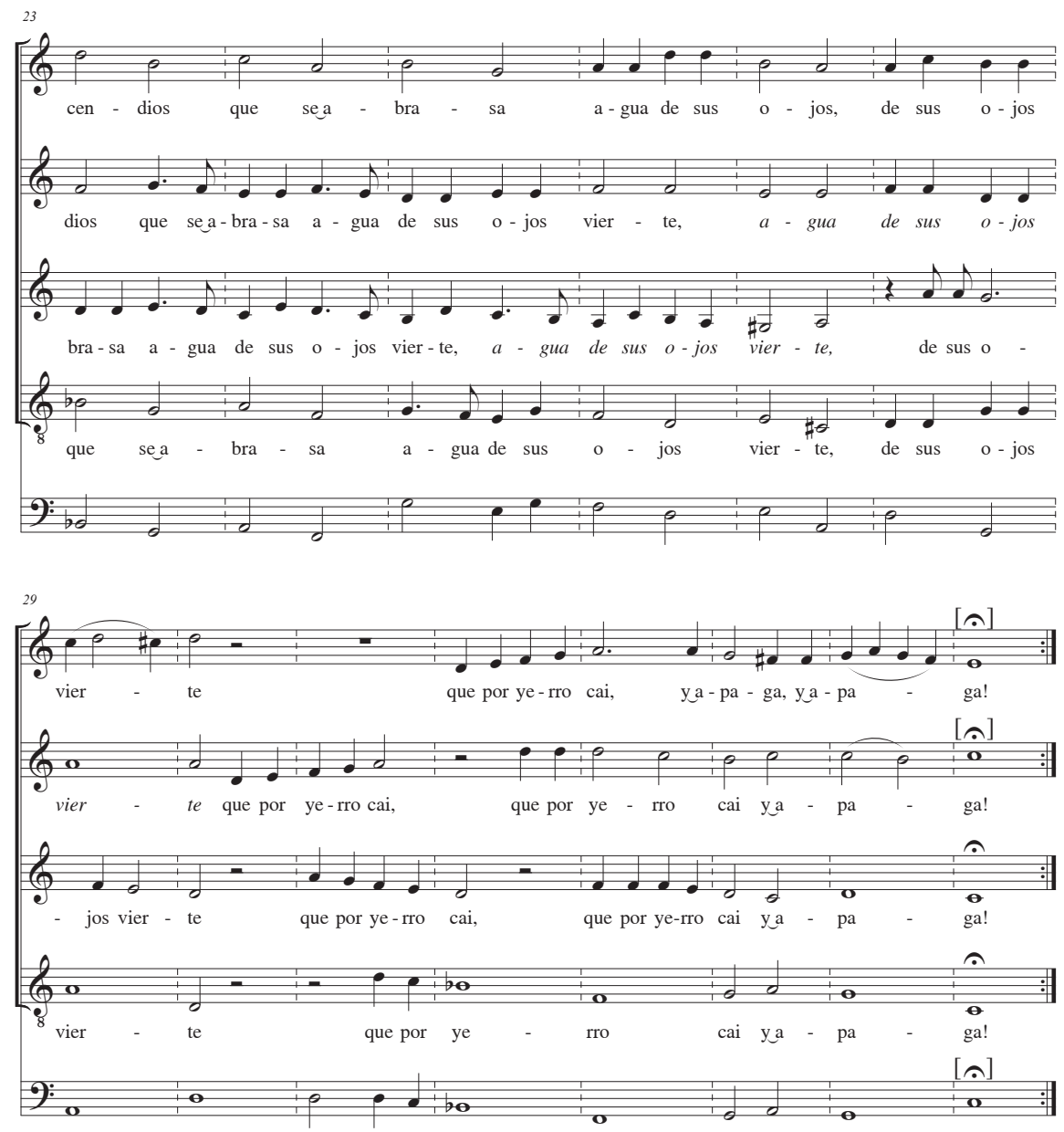

$3^{\mathrm{a}}$. Mortales, aquí de amor es en quien cifra la esperanza, por lo que a lo tierno logra lo infinito que afianza.

$4^{\mathrm{a}}$. Alientos que con suspiros en el aire nos derrama, como de su amor son señas, el cariño los alcanza. 

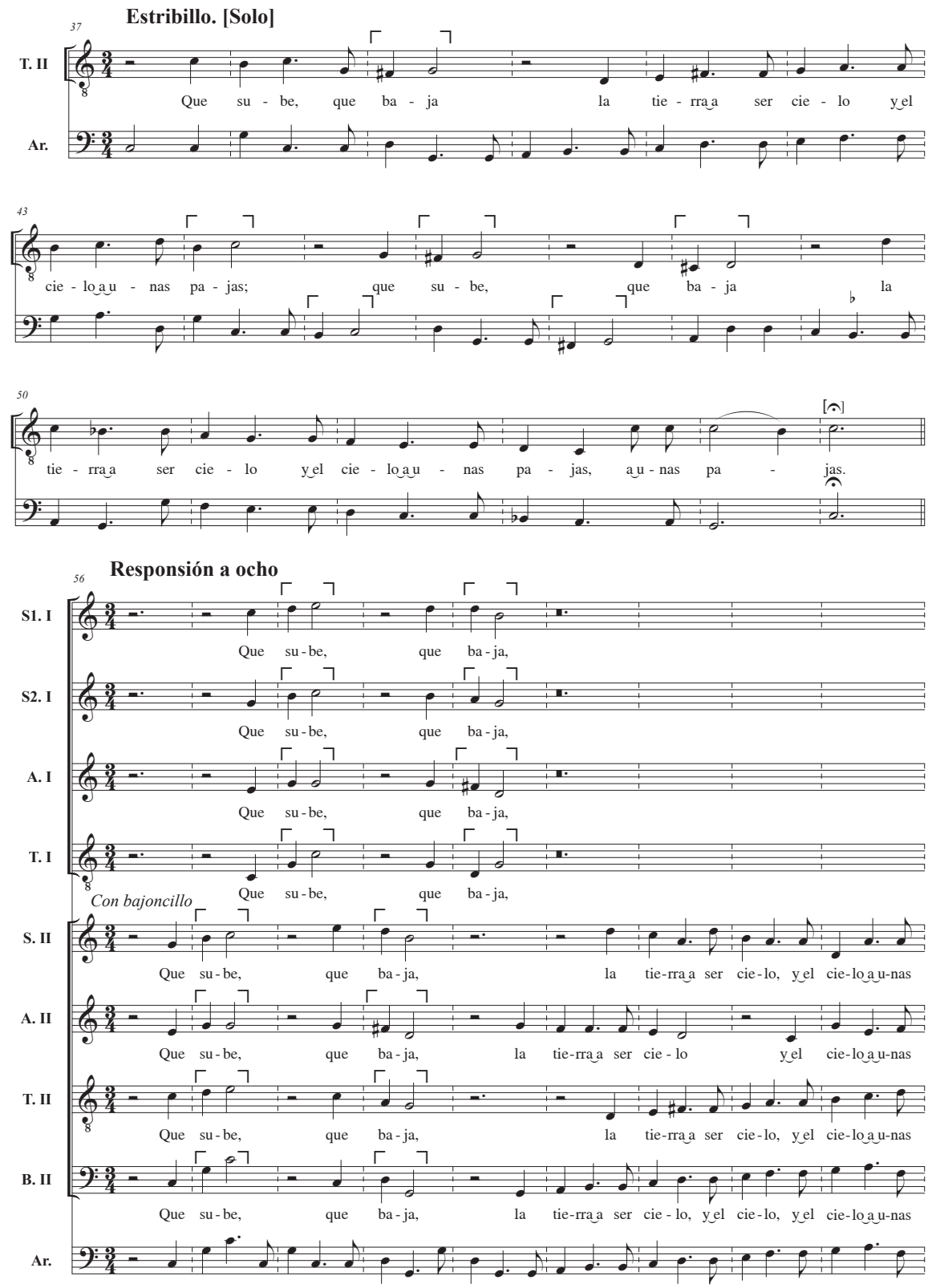

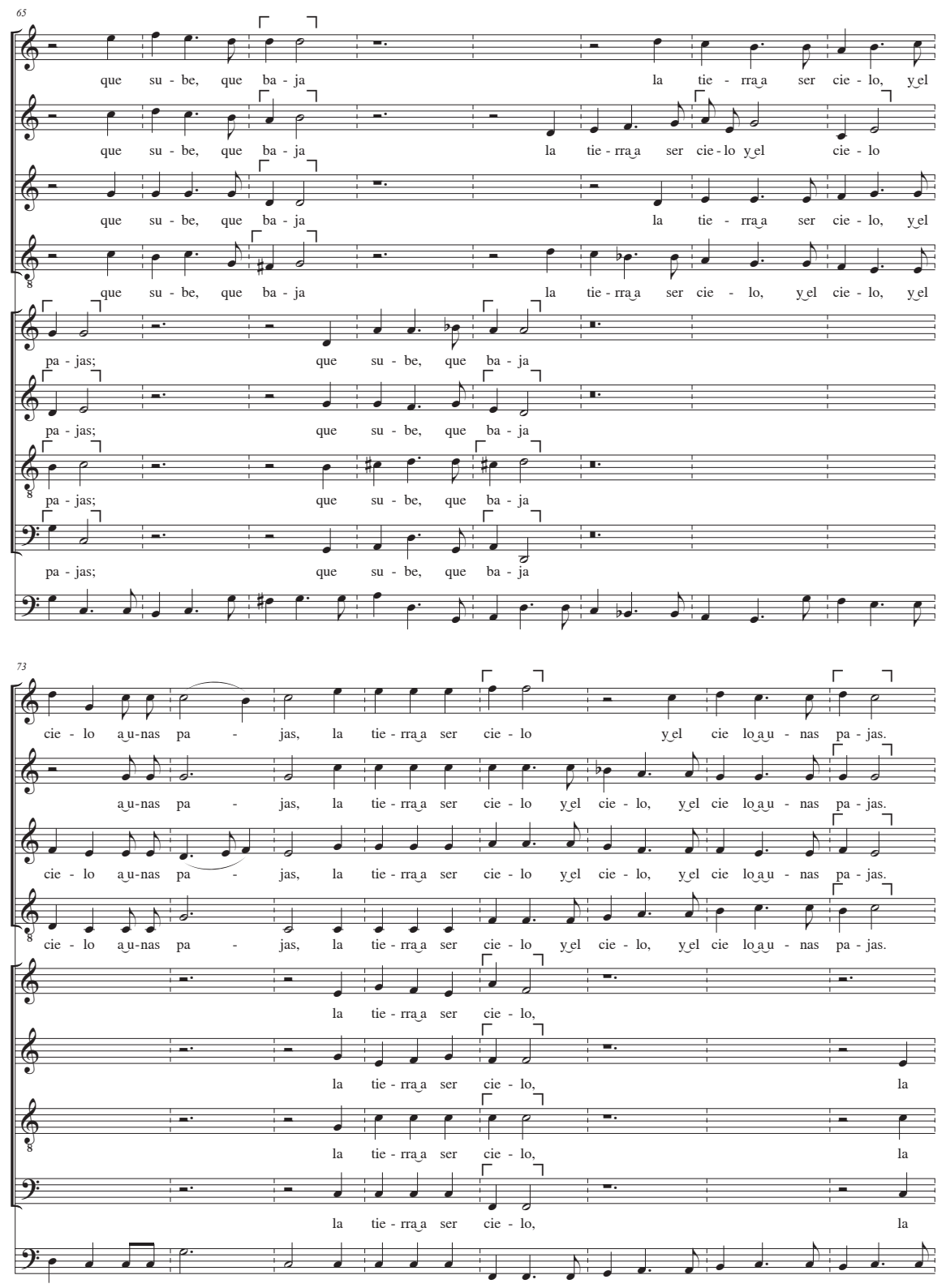


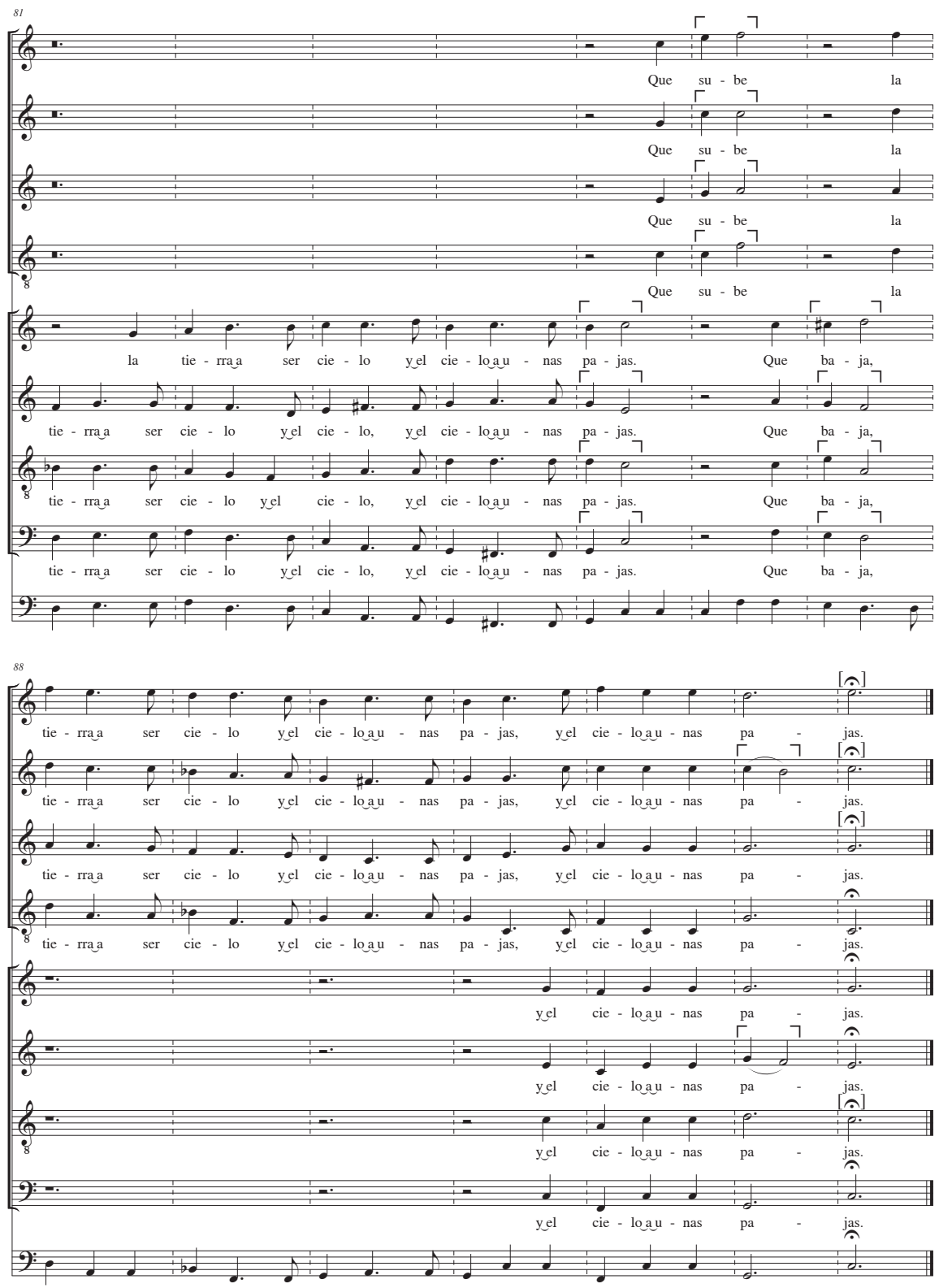

Faltan las Coplas 4 y 5 y la vuelta al Estribillo 


\section{Bibliografia}

Anglés, Higinio; SubirÁ, José: Catálogo musical de la Biblioteca Nacional de Madrid, 3 vols., Barcelona, Consejo Superior de Investigaciones Científicas, Instituto Español de Musicología, 1946-1951.

Arriaga, Gerardo: “Francisco y Gabriel Guerau, músicos mallorquines”, Revista de Musicología, 7, 2, 1984, pp. 253-299.

Caballero Fernández-Rufete, Carmelo (ed.): “Arded, corazón, arded”. Tonos humanos del Barroco en la Península Ibérica, Las Edades del Hombre / Sociedad "V Centernario del Tratado de Tordesillas", 1997.

—: “"En el principio era el verso': textos de villancicos en la catedral de Valladolid (16401725)", Revista de Musicología, 42, 2, 2019, pp. 533-570.

—: "El manuscrito Gayangos-Barbieri”, Revista de Musicología, 12, 1989, pp. 199-268.

-: "En el bufete de Miguel Gómez Camargo. Circulación de repertorios poético-musicales en España en la segunda mitad del siglo XVII”, Ámbitos artísticos y literarios de sociabilidad en los Siglos de Oro, Elena Martínez Carro, Alejandra Ulla Lorenzo (eds.), Kassel, Reichenberger, 2020, pp. 121-138.

—: "Miscent sacra profanis: música profana y teatral en los villancicos de la segunda mitad del siglo XVII”, Música y literatura en la Península Ibérica: 1600-1750. Actas del Congreso Internacional, Valladolid, 20-21 y 22 de febrero, 1995,Valladolid, Sociedad "V Centenario del Tratado de Tordesillas" / Universidad de Valladolid, 1997, pp. 151-167.

—: "Nuevas fuentes musicales de 'Los celos hacen estrellas', de Juan Vélez de Guevara”, Cuadernos de Teatro Clásico, 3,1989, pp. 119-155.

Calderón de la Barca, Pedro; Bianco, Baccio del: Andrómeda y Perseo: fábula escénica, Rafael Maestre (ed.), Almagro, Museo Nacional del Teatro, 1994.

Ellis, Katharine: "The Sociology of Music", An Introduction to Music Studies, J. P. E. Harper-Scott, Jim Samson (eds.), Cambridge, Cambridge University Press, 2009, pp. 52-55.

Gallardo, Bartolomé José: Ensayo de una biblioteca española de libros raros y curiosos, tomo II, Madrid, Rivadeneyra, 1866.

JosA, Lola; LAmbeA, Mariano (eds.): Juan Hidalgo (1614-1685):Tonos y villancicos, Madrid, Dairea Ediciones, 2017.

—: "Tonos humanos teatrales en el Cancionero Poético-Musical de Mallorca (CPMM) (finales del siglo XVII-principios del siglo XVIII)", Rumbos del hispanismo en el umbral del Cincuentenario de la AIH, IV. Teatro, Debora Vaccari (ed.), Roma, Bagatto Libri, 2012, pp. 143-151.

KoEGEL, John: "New Sources of Music from Spain and Colonial Mexico at the Sutro Library", Notes, 55, 3, 1999, pp. 583-613.

López-Calo, José: La Música en la Catedral de Valladolid. Catálogo del Archivo de Música, 7 vols., Valladolid, Ayuntamiento de Valladolid, 2007.

Pedrell, Felipe: Teatro lírico español anterior al siglo XIX, vols. IV-V, La Coruña, Canuto Berea y Compañía, 1898.

—: Teatro lírico español anterior al siglo XIX, vol. III, La Coruña, Canuto Berea y Compañía, 1897. PizÀ,Antoni: Francesc Guerau i el seu temps, Palma de Mallorca, Institut d'Estudis Baleàrics, 2000. 
Reichenberger, Kurt; Reichenberger, Roswitha: Bibliographisches Handbuch der Calderón-Forschung, Kassel, Thiele \& Schwarz, 1979.

SAGE, Jack: "La música de Juan Hidalgo para 'Los celos hacen estrellas' de Juan Vélez de Guevara”, Los celos hacen estrellas, John E. Varey, Norman D. Shergold (eds.), Londres, Támesis Books, 1970, pp. 169-223.

Stein, Louise K.: Songs of Mortals, Dialogues of the Gods. Music and Theatre in Seventeenth-Century Spain, Oxford, Clarendon Press, 1993.

Torrente, Álvaro; Rodríguez, Pablo-L.: “The 'Guerra Manuscript' (c. 1680) and the Rise of Solo Song in Spain”, Journal of the Royal Musical Association, 123, 2, 1998, pp. 147-189.

VÉLEZ de Guevara, Juan: Los celos hacen estrellas, John E.Varey, Norman D. Shergold (eds.), con una edición y estudio de la música de Jack Sage, Londres, Tamesis Books, 1970.

WIEL, Taddeo: I codici musicali Contariniani del secolo XVII nella R. Biblioteca di san Marco in Venezia,Venezia, 1888.

YAKeley, June: "New Sources of Spanish Music for the Five-Course Guitar", Revista de Musicología, 19, 1-2, 1996, pp. 267-286.

Recibido: 13-4-2021

Aceptado: 30-6-2021 